\title{
CASO CPAE: Plan Estratégico 2015 - 2020 centrado en el liderazgo y la gestión de los grupos de interés
}

Rafael Pérez-Uribe

Hugo Alfonso Vargas

Héctor Díaz

\section{Resumen}

7 sta investigación aplicada en el Consejo Profesional de Administración de Empresas (CPAE), entre finales de 2014 y hasta mediados de 2016, tuvo dos fases. En la primera (2014-2015), se realizó el diagnóstico y la estructuración de la planeación estratégica; y en la segunda, la implementación del direccionamiento estratégico (año 2016).

\section{Antecedentes}

\section{E} Consejo Profesional de Administración de Empresas, creado mediante la Ley 60 de 1981, es una entidad de orden nacional adscrita al despacho del Ministro de Comercio, Industria y Turismo. Está encargado de proteger y promover el ejercicio legal de las profesiones de Administración de Empresas, Administración de Negocios y otras denominaciones aplicables, a través de la expedición de la matrícula profesional y aplicación del código de ética correspondiente. En consecuencia, podrá: fomentar la calidad académica, promover y servir de apoyo al desarrollo de la investigación en los campos asociados con la administración, derivando de ello su contribución a la productividad, desarrollo empresarial y social del país.

Rafael Pérez-Uribe

PhD. en Ciencias Empresariales, Universidad Antonio de Nebrija; DEA en economía aplicada, Universidad Nebrija; MGO, Universidad EAN; MSc, Universidad de Quebec a Chicoutimi; Especialista en Evaluación y Construcción de Indicadores de Gestión para la Educación Superior, Escuela de Administración de Negocios; estudios de postgrado como Kenkyusei -nvestigador adscrito- en control total de la calidad y círculos de calidad, Universidad de Fukushima, Japón. Administrador de Empresas, Universidad Jorge Tadeo Lozano. Profesor titular y director del grupo de investigación en gerencia para las grandes, pequeñas y medianas empresas, Universidad EAN.

\section{Hugo Alfonso Vargas}

Magíster en Gerencia Estratégica y Prospectiva; especialista en Gerencia Financiera; Economista, Universidad Jorge Tadeo Lozano. Investigador del G3PyMEs, Universidad EAN.

\section{Hector Díaz}

PhD. en Ciencias Económicas y Empresariales, Universidad Pontificia Comillas; especialista en Finanzas Privadas, Colegio Mayor de Nuestra Señora del Rosario; ingeniero industrial, Pontificia Universidad Javeriana - Puj - Sede Bogotá. Profesor titular e investigador del grupo de investigación G3PyMEs, Universidad EAN. 
En particular y dadas las situaciones presentadas en los años de vigencia del consejo, merece especial atención la extensión a la cobertura de los profesionales, inicialmente previstos en la ley 60, dado que con ocasión de la Sentencia T-207 de 2010, la honorable Corte Constitucional, mediante fallo proferido el 23 de marzo de 2010, en su artículo tercero ordenó: "PREVENIR al Consejo Profesional de Administración de Empresas (CPAE), para que tome las medidas que permitan la homologación del título de Administrador de Empresas con otros debidamente autorizados, del mismo objetivo, similar denominación y equiparables contenidos académicos». En consecuencia, la principal actividad del consejo se circunscribe a la expedición de las matriculas profesionales en el marco de la ley 60 de 1981, la ley 20 de 1988 y previendo las circunstancias planteadas en la sentencia T-207 de 2010. En armonía con lo citado, el consejo complementa su labor atendiendo las demás funciones que le fueron asignadas en la ley:

- Colaborar con el Gobierno Nacional y demás autoridades de la educación superior, en el estudio y establecimientos de los requerimientos académicos curriculares adecuados para la óptima educación y formación de los Administradores de Empresas.

- Participar con las autoridades competentes en la supervisión y control de las entidades de Educación Superior en lo correspondiente a la profesión de Administración de Empresas.
- Dictar el código ético de la Profesión de Administrador de Empresas y su respectiva reglamentación.

- Conocer las denuncias que se presenten contra la ética Profesional y sancionarlas conforme se reglamente.

- Denunciar ante las autoridades competentes las violaciones comprobadas a las disposiciones legales que reglamentan el ejercicio profesional de la Administración de Empresas y solicitar las sanciones que la ley ordinaria fije para los casos del ejercicio ilegal de las profesiones.

- Cooperar con las Asociaciones de Administradores de Empresas en el estímulo y desarrollo de la profesión y el continuo mejoramiento de la calificación de los profesionales de la Administración de Empresas.

- Servir de unidad promotora y orientadora de las investigaciones científicas, a nivel empresarial y docente, sobre los campos de la Administración de Empresas.

- Dictar su propio reglamento, estructurar su funcionamiento, organizar su propia Secretaria Ejecutiva y fijar sus normas de financiación.

- Las demás que señalen las leyes y los decretos del Gobierno Nacional.

Para atender el mandato anterior, la estructura funcional del consejo está organizada de la siguiente manera (Figura 1): 
Figura 1. Organigrama funcional del Consejo.

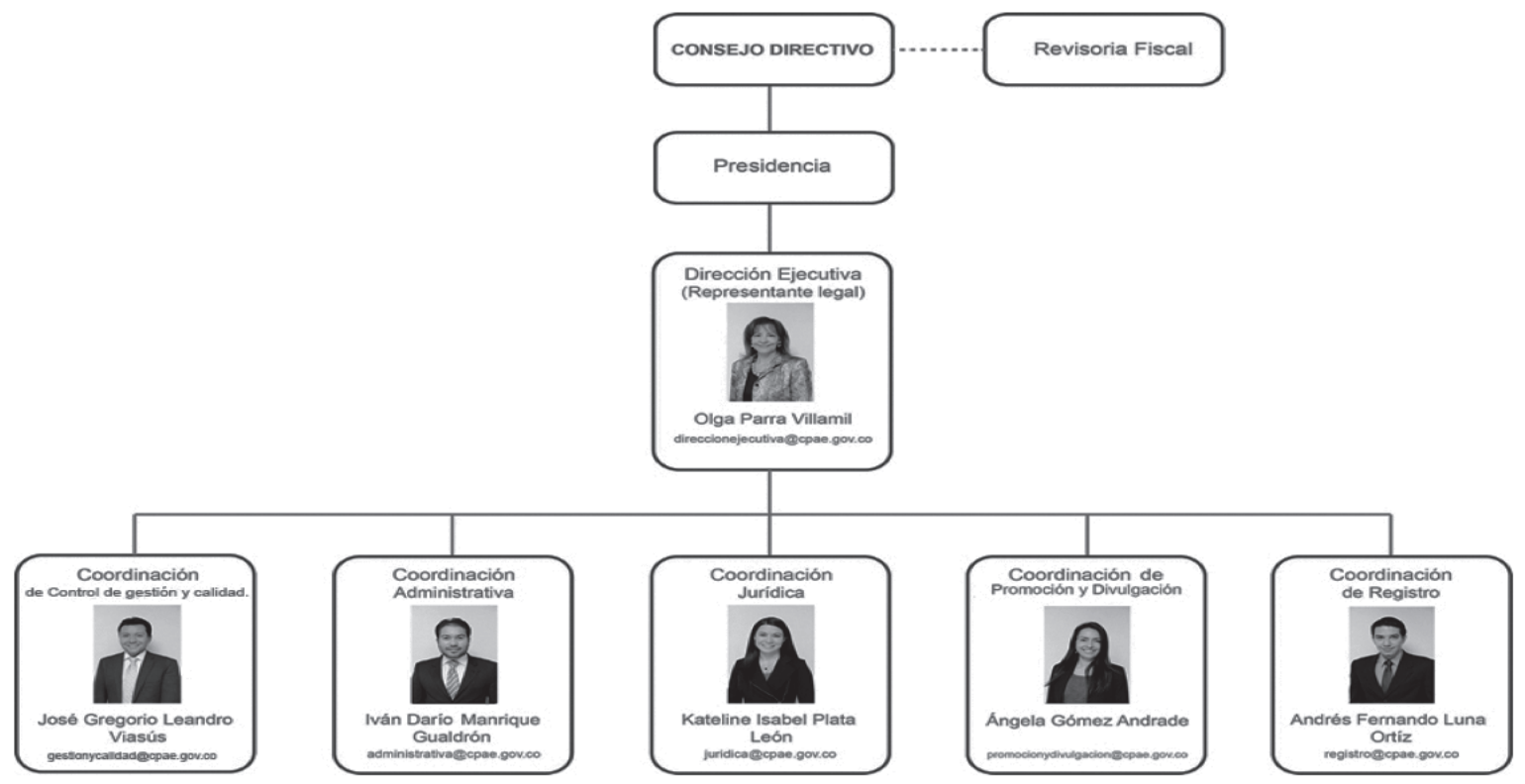

Fuente. Documentos Consejo profesional de administración de empresas, (s.f).

\section{Fase I: el diagnóstico y la planeación}

$\mathrm{E}$

n esta fase se presenta el informe resultante de la labor desarrollada con la dirección y coordinaciones del Consejo Profesional de Administración de Empresas (CPAE), cuyo propósito fundamental consistió en desarrollar el plan estratégico denominado «Centrados en el Liderazgo y la gestión de grupos de interés 2020».

El desarrollo de esta fase se dividió en los siguientes aspectos: el reconocimiento de los fundamentos y actividad del consejo, la formulación de estrategias, la documentación, y finalmente, la elaboración del plan de acción general. Más allá de las definiciones estratégicas y el plan de acción respectivo, radicó en la construcción conjunta con la dirección y diferentes coordinaciones, haciendo un despliegue de las expectativas, ideas y desarrollos ya germinados en el consejo, situación que facilitó la labor y además empodero al grupo, para la ejecución del plan de acción previsto.

Así, se fijó la línea y orientación en el proceso de implementación y estructuración del marco de monitoreo y control de las acciones previstas desde la óptica de proyectos, programas y/o actividades, que emergerán con ocasión del trabajo realizado. 


\section{Preliminares}

I I resultado de la información obtenida de Llos coordinadores, las prácticas y métodos elegidos para el acopio de información, así como la dinámica de equipo de trabajo desarrollada con tres de las coordinaciones más representativas del Consejo, llevó a los siguientes hallazgos que fueron claves para el desarrollo de los objetivos corporativos y las definiciones que aquí presentamos.

En primer lugar y para dar un sentido a la exploración inicial, se definió un método de trabajo que consistió en restablecer la reciente historia del Consejo, con el ánimo de dirigir la atención hacia lo que sus integrantes visualizan, en lo que tienen motivación, y además, en lo que se diferenciaría el mismo Consejo de entidades similares siempre en el marco de la ley y con enfoque en el desarrollo de actividades que generen valor para los beneficiarios naturales del consejo, los profesionales registrados.

Más adelante (Figura 2), resalta el método seguido para poder reconocer la organización, establecer en conjunto sus realizaciones, sus problemas, sus iniciativas y frustraciones, con el objeto de recoger estas lecciones y orientar la labor de planeación estratégica encomendada.

Figura 2. Definiciones básicas

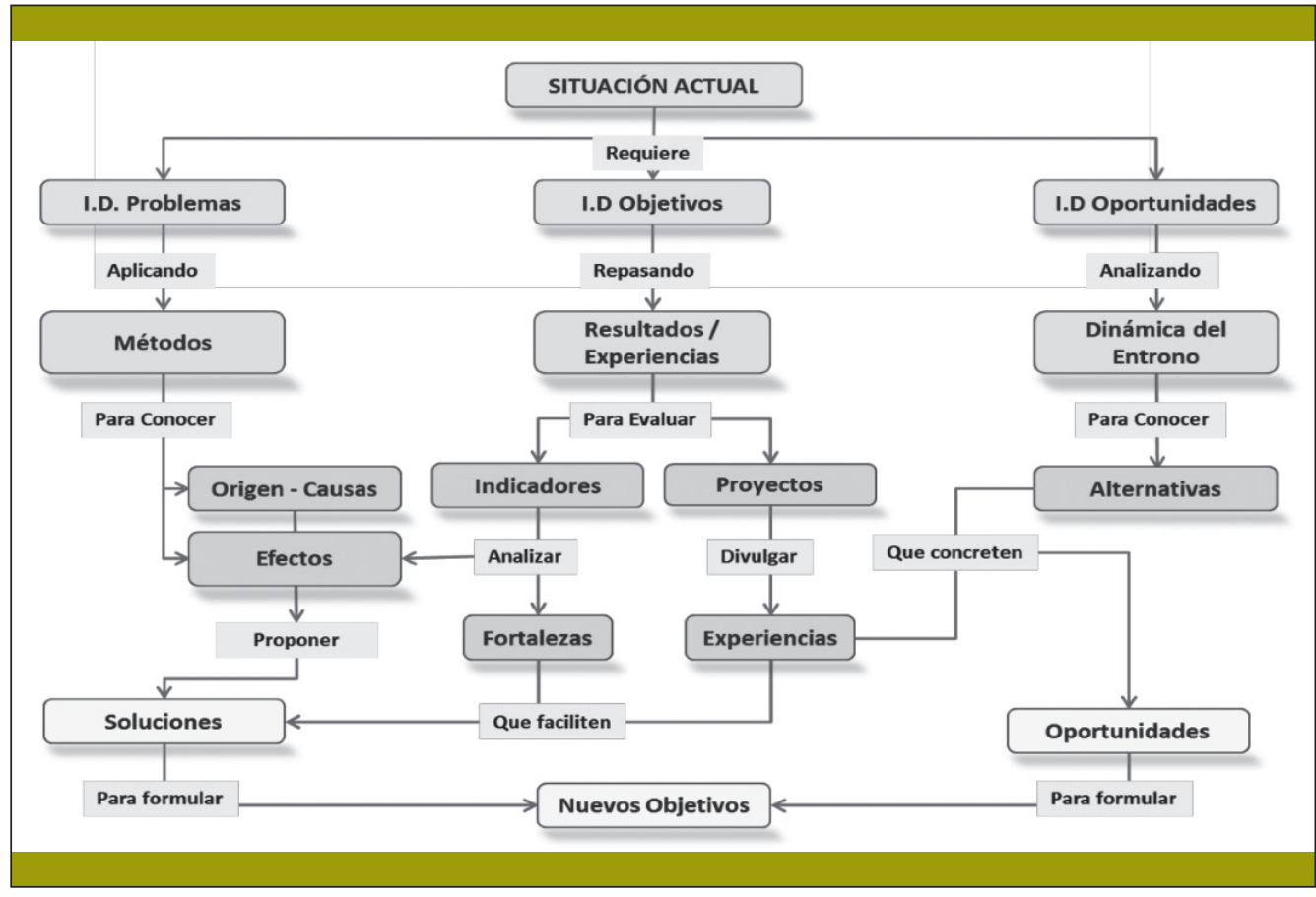

Fuente. Elaborado por el equipo de planeación estratégica, Consejo, (s.f).

Vale la pena resaltar que las guías fundamentales apuntan a reconocer los problemas, los objetivos y las oportunidades de y para el desarrollo del Consejo. Esta exploración llevó a identificar varios factores que resumían los aspectos citados, los cuales se organizaron y sintetizaron a continuación (Tabla 1). 
Tabla 1. Definición de factores.

\begin{tabular}{|c|c|c|c|}
\hline \multicolumn{4}{|r|}{ Matriz de factores y descriptores } \\
\hline Factores & No. & Cod. & Descripción \\
\hline Competencias & 1 & Cp 1 & $\begin{array}{l}\text { Es la capacidad individual o colectiva, que soporta el desempeño del consejo. Se basa en la inte- } \\
\text { gración y activación de conocimientos, habilidades, destrezas, actitudes y valores dispuestos allí. }\end{array}$ \\
\hline Desarrollo T.H. & 2 & Dth 2 & $\begin{array}{l}\text { Es la función desplegada, que pretende el desarrollo de la capacidad de los individuos, la } \\
\text { profundización del compromiso y la predisposición de las habilidades convertidas en acciones } \\
\text { generadoras de valor en y para el consejo. }\end{array}$ \\
\hline Divulgación & 3 & Dv 3 & $\begin{array}{l}\text { Referencia el material, o cualquier otra forma de contenido o presentación, alusivo a la } \\
\text { misión del consejo, que tenga por objeto mantener informados a los grupos de interés. }\end{array}$ \\
\hline Infraestructura & 4 & If 4 & $\begin{array}{l}\text { Conjunto de equipamientos físicos y de recursos sobre los cuales se apoya la gestión del } \\
\text { consejo. }\end{array}$ \\
\hline $\begin{array}{l}\text { Infraestructura } \\
\text { tecnológica. }\end{array}$ & 5 & It 5 & Conjunto de equipamientos tecnológicos sobre los cuales se apoya la gestión del consejo. \\
\hline Liderazgo & 6 & Li 6 & $\begin{array}{l}\text { Es el conjunto de habilidades de cada individuo, que usa para influir, convocar y compartir, } \\
\text { en torno de los objetivos comunes del consejo. }\end{array}$ \\
\hline Normativa & 7 & $\mathrm{Nm} 7$ & Conjunto de normas definidas y aplicadas al funcionamiento del consejo. \\
\hline Procesos & 8 & $\operatorname{Pr} 8$ & Actividades, relacionadas y articuladas, que tienen como fin resultados concretos. \\
\hline $\begin{array}{l}\text { Reglamentación } \\
\text { interna. }\end{array}$ & 9 & Ri 9 & Son patrones de conducta, normas y políticas, que rigen regulan las actividades del consejo. \\
\hline $\begin{array}{l}\text { Sostenibilidad } \\
\text { financiera. }\end{array}$ & 10 & Sf 10 & $\begin{array}{l}\text { Hace referencia a la capacidad y permanencia de la generación de ingresos. Es un } \\
\text { componente clave de la sostenibilidad de la organización, que junto con la sostenibilidad } \\
\text { técnica y administrativa, permiten la dinámica y vigencia del consejo. }\end{array}$ \\
\hline $\begin{array}{l}\text { Gestión de } \\
\text { los grupos de } \\
\text { interés. }\end{array}$ & 11 & Gs 11 & $\begin{array}{l}\text { Es la capacidad que despliega el consejo, para entender y atender los intereses, tanto directos } \\
\text { como indirectos de los grupos de interés. Actividad fundamental si se tiene en cuenta el } \\
\text { objeto y objetivo del consejo, los dos enfocados, más en la mejor distribución de los recursos } \\
\text { obtenidos, que en la generación de los mismos. }\end{array}$ \\
\hline $\begin{array}{l}\text { Agilidad } \\
\text { transaccional. }\end{array}$ & 12 & At 12 & Es la situación deseada en el consejo, en la búsqueda de la eficiencia y productividad. \\
\hline
\end{tabular}

Fuente. Elaborado por el equipo de planeación estratégica, Consejo, (s.f).

A partir de los datos presentados anteriormente, se procedió a caracterizar y fundamentar las variables correspondientes con el fin de orientar en mejor forma la labor; para ello obtuvimos la siguiente información (Tabla 2):

Tabla 2. Desde el punto de vista de la problemática e iniciativas del Consejo

\section{A. Caracterización de problemas}

\begin{tabular}{|c|c|c|c|c|c|c|c|c|c|}
\hline \multicolumn{6}{|c|}{ LÍNEA DE BASE - Percepción General } & \multicolumn{4}{|c|}{ Principales problemas } \\
\hline \multirow[t]{2}{*}{ Detalle } & \multicolumn{3}{|c|}{ Proceso Adtivo } & \multicolumn{2}{|r|}{ Total } & \multicolumn{2}{|c|}{ Proceso Adtivo } & \multicolumn{2}{|c|}{ Total } \\
\hline & $p$ & 0 & $D$ & & & $p$ & $D$ & & \\
\hline Crear valor & 11 & & & 11 & $20,0 \%$ & 3 & 1 & 4 & $28,6 \%$ \\
\hline Codigo de Etica & & 3 & 2 & 5 & $9,1 \%$ & 1 & & 1 & $7,1 \%$ \\
\hline Infraestructura & & 3 & & 3 & $5,5 \%$ & & & 0 & $0,0 \%$ \\
\hline Liderazgo & & & 6 & 6 & $10,9 \%$ & 2 & & 2 & $14,3 \%$ \\
\hline Normatividad & 1 & & 1 & 2 & $3,6 \%$ & & & 0 & $0,0 \%$ \\
\hline Procesos & & 1 & 3 & 4 & $7,3 \%$ & 1 & & 1 & $7,1 \%$ \\
\hline Infraestructura tecnologica & & 8 & & 8 & $14,5 \%$ & 4 & & 4 & $28,6 \%$ \\
\hline \multirow[t]{2}{*}{ Reglamentación Interna } & 1 & 11 & 2 & 16 & $29,1 \%$ & 2 & & 2 & $14,3 \%$ \\
\hline & 13 & 26 & 115 & 55 & & 5 & 1 & 14 & \\
\hline
\end{tabular}

B. Caracterización de iniciativas

\begin{tabular}{|c|c|c|c|c|c|c|c|c|c|c|c|c|}
\hline \multicolumn{7}{|c|}{ LÍNEA DE BASE - Iniciativas Desarrolladas } & \multicolumn{6}{|c|}{ Iniciativas No Desarrolladas } \\
\hline \multirow[t]{2}{*}{ Detalle } & \multicolumn{4}{|c|}{ Proceso Adtivo } & \multicolumn{2}{|c|}{ Total } & \multicolumn{4}{|c|}{ Proceso Adtivo } & \multicolumn{2}{|c|}{ Total } \\
\hline & $p$ & 0 & $D$ & $c$ & & & $p$ & 0 & $D$ & c & & \\
\hline Codigo de Etica & 2 & & & & 2 & $8,7 \%$ & 1 & & & & 1 & $4,8 \%$ \\
\hline Crear valor & & & & & & $0,0 \%$ & 6 & & & & & $0,0 \%$ \\
\hline Infraestructura & & 2 & & & 2 & $8,7 \%$ & & 1 & & & 1 & $4,8 \%$ \\
\hline Liderazgo & 2 & & 4 & & 6 & $26,1 \%$ & 4 & & 4 & & 8[ & $38,1 \%$ \\
\hline Normatividad & 1 & & & & 1 & $4,3 \%$ & 1 & 1 & & & 2 & $9,5 \%$ \\
\hline Procesos & & & & 1 & 1 & $4,3 \%$ & & & & & 0 & $0,0 \%$ \\
\hline Infraestructura tecnologica & & 9 & & & 9 & $39,1 \%$ & & 6 & & & 6 & $28,6 \%$ \\
\hline \multirow[t]{2}{*}{ Reglamentación Interna } & 2 & & & & 2 & $8,7 \%$ & 1 & 2 & & & 3 & $14,3 \%$ \\
\hline & 7 & 11 & 4 & 1 & 23 & & 13 & 10 & 4 & 0 & 21 & \\
\hline
\end{tabular}

Fuente. Elaborado por el equipo de planeación estratégica, Consejo, (s.f). 
La información anterior, se calificó en función de la frecuencia de las observaciones manifestadas por cada uno de los cinco coordinadores planteados en diferentes instancias del trabajo realizado. Las columnas sombreadas resaltan el problema e iniciativas, en función del proceso administrativo del consejo

Como se observa (Tabla 2-A), hay coincidencia en orientar la labor de equipo internamente, con el objeto de liderar el desarrollo de una mejor oferta con valor para los usuarios y beneficiarios de la actividad del consejo, atendiendo y mejorando el proceso de reglamentación internay la dotación, adecuación y articulación de la infraestructura tecnológica. Luego, (Tabla 2-B), se repite la misma realidad con una situación muy importante y es que no se han desarrollado iniciativas que induzcan a la generación de valor en el Consejo, dejando entrever una dinámica centrada en el cumplimiento de la labor rutinaria.

Tabla 3. Desde el punto de vista del diagnóstico estratégico.

\begin{tabular}{|c|c|c|c|c|c|c|c|c|c|c|c|c|c|c|c|c|c|c|c|c|c|c|c|}
\hline \multicolumn{11}{|c|}{ A. Análisis Interno } & \multicolumn{13}{|c|}{ B. Análisis Externo } \\
\hline \multicolumn{6}{|c|}{ DIAGNOSTICO ESTRATEGICO, ANÁLISIS INTERNO - Debilidades } & \multicolumn{5}{|c|}{ ANÁLISIS INTERNO - Fortalezas } & \multicolumn{7}{|c|}{ DIAGNOSTICO ESTRATEGICO, ANÁLLSIS EXTERNO - Amenazas } & \multicolumn{6}{|c|}{ ANÁLISIS EXTERNO - Oportunidades } \\
\hline \multirow[t]{2}{*}{ Detalle } & \multicolumn{4}{|c|}{ Proceso Adtivo } & Total & \multicolumn{4}{|c|}{ Proceso Adtivo } & Total & \multirow[t]{2}{*}{\begin{tabular}{|c|} 
Detalle \\
\end{tabular}} & \multicolumn{4}{|c|}{ Proceso Adtivo } & \multirow{2}{*}{\multicolumn{2}{|c|}{ Total }} & \multicolumn{4}{|c|}{ Proceso Adtivo } & \multicolumn{2}{|c|}{ Total } \\
\hline & $p$ & 0 & D & $c$ & & $p$ & 0 & $D$ & $c$ & & & $P$ & 0 & $D$ & C & & & p & 0 & D & c & & \\
\hline Desarrollo de TH & & & 3 & & $\begin{array}{ll}3 & 10,7 \%\end{array}$ & & 1 & 3 & & $21,1 \%$ & Codigo Etica & & 2 & & & 2 & $6,5 \%$ & & & & & 0 & $0,0 \%$ \\
\hline Infraestructura & & 2 & & & $27,1 \%$ & & 1 & & & $5,3 \%$ & Creación de Valor & & & & & 0 & $0,0 \%$ & 4 & & & & 4 & $\overline{1} 18,2 \%$, \\
\hline Inf. Tecnologica & 1 & 1 & & & $27,1 \%$ & 1 & 2 & 1 & & $4 \longdiv { 2 1 , 1 \% }$ & Inf. Tecnologica & 1 & 3 & 1 & & 5 & $16,1 \%$ & & 2 & 1 & & 3 & $13,6 \%$ \\
\hline Procesos & 1 & 5 & 1 & 11 & $1 8 \longdiv { 6 4 , 3 \% }$ & & 1 & & 4 & $26,3 \%$ & Liderazgo & 3 & 1 & 6 & & 10 & $32,3 \%$ & 1 & & 4 & & 5 & $22,7 \%$ \\
\hline Liderazgo & & & & & $0 \quad 0,0 \%$ & & & 3 & & $15,8 \%$ & Sostenibilidad Fciera & 5 & & & & 5 & $16,1 \%$ & 1 & & & & 1 & $4,5 \%$ \\
\hline Sostenibilidad Fciera & & & & & $0 \quad 0,0 \%$ & & 2 & & & $10,5 \%$ & Normatividad & 4 & 1 & & 1 & 6 & $19,4 \%$ & 3 & 2 & 4 & & 9 & $40,9 \%$ \\
\hline \multirow[t]{2}{*}{ Reglamentación Interna } & & 3 & & & $310,7 \%$ & & & & & $0,0 \%$ & Reglamentación Interna & & 3 & & & 3 & $9,7 \%$ & & & & & 0 & $0,0 \%$ \\
\hline & 2 & 11] & 4 & 111 & 28 & 1 & 7 & 7 & 4 & 19 & & 13 & 10 & 7 & 1 & 31 & & 9 & 4 & 9 & 0 & 22 & \\
\hline
\end{tabular}

Fuente. Elaborado por el equipo de planeación estratégica, Consejo, (s.f).

Desde el punto de vista del análisis interno (Tabla 3-B), es evidente la debilidad en procesos, allí se concentró el grueso de las observaciones, pero además referidos a la parte de Control y organización. Hay un contrasentido en lo referente a la infraestructura tecnológica, situación que se explica en las iniciativas llevadas a cabo de manera no articulada (Tabla 3), porque no se había configurado un proyecto que cubriera las expectativas presentes y futuras de la organización y los desarrollos e inversiones sueltas, habían dado una ilusión de fortaleza, que en realidad resaltaba más una situación importante de mejora. Sin duda, las fortalezas evidentes fueron el liderazgo individual y la certidumbre presente de la generación de ingresos.
De información anterior, se retoman como factores relevantes la creación de valor, liderazgo, sostenibilidad financiera y normatividad. Para hacer una lectura juiciosa del diagnóstico hay que interpretar los tres primeros factores de manera conjunta. Así las cosas, se reafirma en el análisis externo la necesidad de generar una oferta con valor y allí, surge como amenaza, el liderazgo, pero también como oportunidad. Evidentemente, se refiere a la necesidad de producto y se reconocen las falencias de capital humano, tecnológicas y organizacionales, para poder habilitar esta capacidad en la organización, reconociendo además que puede afectar la sostenibilidad futura del consejo. 
Caso aparte es la normatividad, la cual está referida a la necesidad de adecuar el marco y definir quehaceres -código de ética- que orientan la actividad misional del Consejo.

Figura 3. Desde el punto de vista de la definición y caracterización de variables.

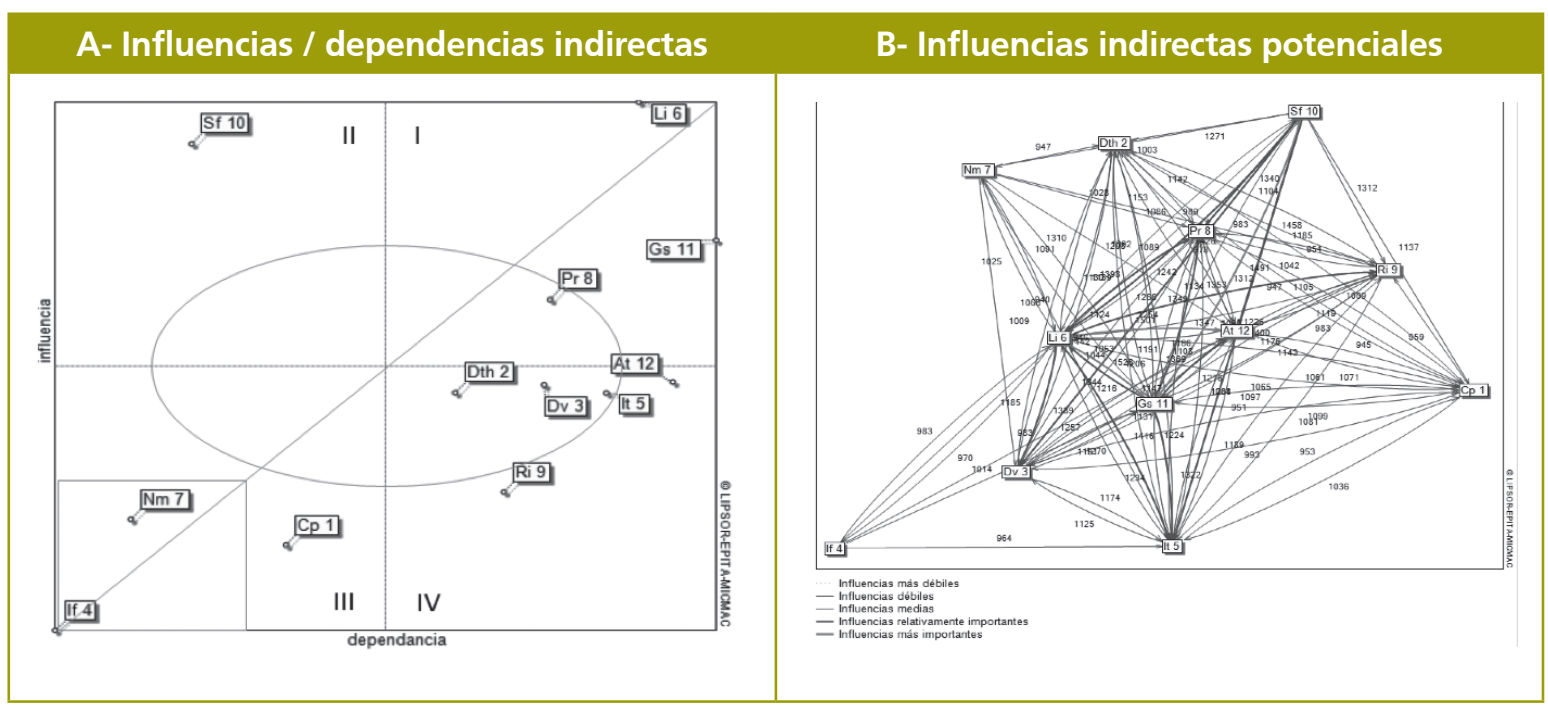

Fuente. Elaborado por el equipo de planeación estratégica, Consejo, (s.f).

Utilizando la metodología de la matriz de impactos cruzados MicMac, se procedió a la caracterización de los factores ya identificados, con el objeto de definir las variables que ayudaran a la configuración del plan estratégico del consejo.

Se muestran (Figura 3 - A) los resultados en los cuatro cuadrantes del diagrama los cuales se interpretan así:

- Cuadrante I. Muestra las variables de alta motricidad y alta dependencia, constituyendo las variables críticas del sistema sobre las que se debe actuar para generar los cambios anhelados en el consejo. Se encuentran allí, el liderazgo y la gestión de los grupos de interés. El liderazgo, junto a la sostenibilidad financiera, aspectos que se analizan en el cuadrante II, incide determinantemente en la variable gestión de grupos de interés, además de constituir las influencias indirectas más importantes (Figura 3).

- Cuadrante II. Allí, se localizan las variables de alta motricidad y poca dependencia, determinando el funcionamiento del sistema. Precisamente es lo que implica la variable sostenibilidad financiera, es la base financiera definida reglamentariamente por la ley, la que le otorga este poder y define su caracterización.

- Cuadrante III. Se encuentran las variables de poca motricidad y poca dependencia, por ello denominadas variables autónomas. Estas son: la infraestructura, las competencias y la normatividad. Son por llamarlas de algún modo las variables prerrequisito para poder sustentar los planes de acción que se formulen. 
- Cuadrante IV. Las variables caracterizadas por una alta dependencia y poca motricidad se denominan las variables de resultado y encontramos allí la variable reglamentación interna y agilidad transaccional. La primera por cuanto en la medida que se defina el norte y las acciones del consejo, permitirá estandarizar las reglas de funcionamiento internas, solucionando las falencias comentadas. De la misma manera, la agilidad transaccional será el resultado de la optimización de los procesos articulando las acciones previstas en el plan.

Es importante resaltar el papel que cumplen las variables contenidas en la elipse. Se denominan variables regulatorias.

La localización de la variable procesos -en la elipse y sobre el cuadrante 1-, implica la necesidad de actuar diligentemente sobre esta dado que va a garantizar la eficiencia y pertinencia sobre las variables críticas de sistema. De la misma manera, las variables localizadas en la parte inferior de la elipse, implican el soporte que se desarrollará para hacer operativa y eficiente la variable procesos y el conjunto en general. Estas son: desarrollo de talento humano, infraestructura tecnológica y divulgación, constituyéndose a su vez en el escenario más importante de formulación de proyectos en el consejo.

\subsection{Sistema de finalidades}

\subsubsection{Visión 2020}

Ser reconocidos como la Institución que fomena el ejercicio ético de la profesión de administración en todas sus áreas de desempeño.

\subsubsection{Misión}

Aunar esfuerzos con las instituciones, en la promoción y fomento del ejercicio de la profesión en Colombia convocando los grupos de interés para la productividad empresarial, con responsabilidad social.

\subsubsection{Valores}

El Consejo Profesional de Administración de Empresas promueve tres características que deben ser inherentes a cada uno de sus profesionales: Integridad, Servicio y Excelencia. Además de lo anterior, los valores de la entidad son:

- Respeto a la dignidad humana.

- Integración y cooperación con instituciones, estamentos y personas.

- Alto sentido ético.

- Responsabilidad en el manejo de los recursos.

- Calidad y equidad en la prestación del servicio.

- Liderazgo en el cumplimiento de sus compromisos.

\subsection{Objetivos corporativos}

Son el marco de referencia de los objetivos funcionales, integran la labor del consejo y de la dirección ejecutiva, por ello, se reflejan en las líneas estratégicas y acciones de las coordinaciones en el consejo, son:

- Ser líderes: desarrollo de competencias internas que permitan el posicionamiento del Consejo. 
- Ser innovadores: desarrollar las nuevas capacidades para soportar la innovación en la propuesta de valor.

- Ser eficientes en la prestación de servicios: tender a cero en las reclamaciones, reprocesos y demás actividades que duplican esfuerzos del consejo.

\subsection{Líneas estratégicas}

Tienen por objeto facilitar el direccionamiento estratégico del Consejo en la medida que se articulan con las acciones a desarrollar y en el periodo contemplado en el plan (Tabla 4).

Tabla 4. Líneas estratégicas.

\begin{tabular}{|c|c|c|c|}
\hline Líneas & Objetivo & Acciones & Lider \\
\hline $\begin{array}{l}\text { Línea } 1 \text { - Gestión, } \\
\text { grupos de interés. }\end{array}$ & $\begin{array}{l}\text { Fortalecer relaciones } \\
\text { con grupos de interés } \\
\text { generando sinergias para la } \\
\text { satisfacción de expectativas } \\
\text { conjuntas }\end{array}$ & $\begin{array}{l}\text { Acción 1: identificar, priorizar y } \\
\text { convocar los grupos de interés. } \\
\text { Acción 2: definir el portafolio } \\
\text { de servicios. } \\
\text { Acción 3: desarrollar y } \\
\text { monitorear la generación de } \\
\text { valores agregados - Apoyo a la } \\
\text { investigación. }\end{array}$ & Comité administrativo. \\
\hline $\begin{array}{l}\text { línea } 2 \text { - } \\
\text { Divulgación }\end{array}$ & $\begin{array}{l}\text { Posicionar la labor del } \\
\text { Consejo frente a los grupos } \\
\text { de interés directos e } \\
\text { indirectos. }\end{array}$ & $\begin{array}{l}\text { Acción 1: establecer canales } \\
\text { de comunicación diversos para } \\
\text { divulgar las actividades del } \\
\text { consejo } \\
\text { Acción 2: establecer un método } \\
\text { de comunicación asertiva, } \\
\text { para difundir el objetivo, valor } \\
\text { y necesidad de contar con el } \\
\text { registro y la T.P. } \\
\text { Acción 3: establecer dinámicas } \\
\text { para realizar eventos que } \\
\text { profundicen la presencia } \\
\text { institucional del Consejo. }\end{array}$ & Promoción y divulgación. \\
\hline $\begin{array}{c}\text { Línea } 3 \text { - } \\
\text { Infraestructura física }\end{array}$ & $\begin{array}{l}\text { Gestionar la adquisición de } \\
\text { infraestructura adecuada } \\
\text { para el funcionamiento del } \\
\text { Consejo; recursos para la } \\
\text { prestación de un servicio } \\
\text { eficiente. }\end{array}$ & & Dirección ejecutiva. \\
\hline $\begin{array}{l}\text { Línea } 4 \text { - } \\
\text { Infraestructura } \\
\text { tecnológica }\end{array}$ & $\begin{array}{l}\text { Disponer de las TIC } \\
\text { pertinentes y adecuadas, } \\
\text { para la prestación eficiente } \\
\text { del servicio }\end{array}$ & $\begin{array}{l}\text { Acción 1: diagnóstico y } \\
\text { definición de necesidades. } \\
\text { Acción 2: formulación del } \\
\text { proyecto TIC. } \\
\text { Acción 3: implementación y } \\
\text { puesta en operación-proyecto } \\
\text { TIC. }\end{array}$ & Comité administrativo \\
\hline $\begin{array}{l}\text { Línea } 5 \text { - } \\
\text { Reglamentación } \\
\text { interna }\end{array}$ & $\begin{array}{l}\text { Dar cumplimiento a los } \\
\text { mandatos legales que } \\
\text { regulan el consejo }\end{array}$ & $\begin{array}{l}\text { Acción 1: código de ética y } \\
\text { ampliación de la raíz en la ley } \\
\text { (Sentencia T-207 de 2010). } \\
\text { Acción 2: mantener la } \\
\text { reglamentación interna } \\
\text { actualizada de acuerdo con los } \\
\text { cambios normativos. }\end{array}$ & $\begin{array}{l}\text { Dirección ejecutiva } \\
\text { Jurídica, Control interno }\end{array}$ \\
\hline
\end{tabular}


Tabla 4. Líneas estratégicas (Continuación)

\begin{tabular}{|c|c|c|c|}
\hline Línea 6 - Procesos & $\begin{array}{l}\text { Contar con procesos } \\
\text { óptimos y agiles, } \\
\text { que cumplan con las } \\
\text { necesidades del consejo }\end{array}$ & $\begin{array}{l}\text { Acción 1: optimizar procesos } \\
\text { existentes. } \\
\text { Acción 2: identificar y } \\
\text { caracterizar procesos necesarios } \\
\text { para cumplir objetivos } \\
\text { estratégicos. } \\
\text { Acción 3: articular los procesos } \\
\text { del consejo, en un cuerpo } \\
\text { integral y alineado con los } \\
\text { grupos de interés. }\end{array}$ & Comité administrativo \\
\hline $\begin{array}{c}\text { Línea } 7 \text { - Gestión, } \\
\text { talento humano }\end{array}$ & $\begin{array}{l}\text { Contar con el recurso } \\
\text { humano idóneo para } \\
\text { el cumplimiento de las } \\
\text { funciones del Consejo }\end{array}$ & $\begin{array}{l}\text { Acción 1: fomentar y formar } \\
\text { la capacidad individual de los } \\
\text { trabajadores. } \\
\text { Acción 2: elaborar planes y } \\
\text { programas de Bienestar } \\
\text { Acción 3: elaborar un plan de } \\
\text { incentivos }\end{array}$ & $\begin{array}{l}\text { Comité Administrativo } \\
\text { Dirección ejecutiva }\end{array}$ \\
\hline $\begin{array}{l}\text { Línea } 8 \text { - } \\
\text { Sostenibilidad } \\
\text { financiera }\end{array}$ & $\begin{array}{l}\text { Contar con los recursos } \\
\text { suficientes para la operación } \\
\text { del Consejo }\end{array}$ & $\begin{array}{l}\text { Acción 1: optimizar y agilizar el } \\
\text { servicio de expedición de TP a } \\
\text { los usuarios. }\end{array}$ & Comité administrativo \\
\hline
\end{tabular}

Fuente. Equipo de planeación.

\subsection{Tips y avances para la operacionalización y control estratégicos}

\subsubsection{Definición de la cadena de valor del Consejo (Figura 4)}

Figura 4. Cadena de valor del Consejo

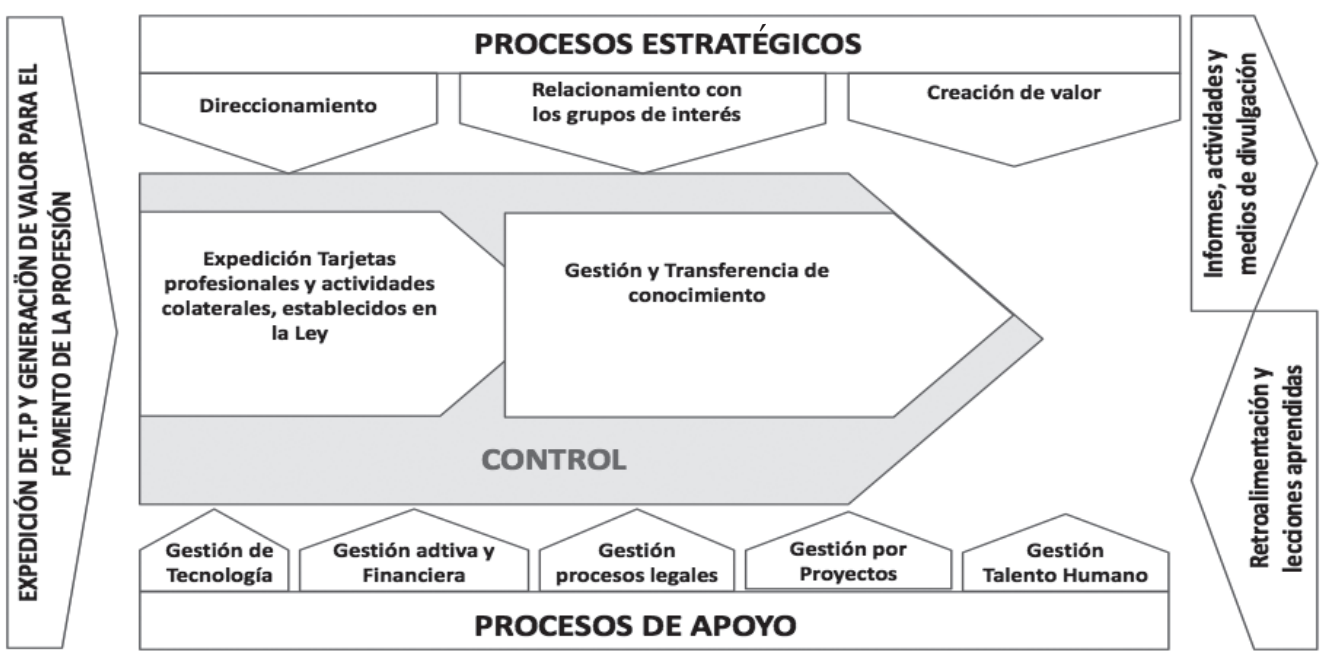

Fuente. Elaborado por el equipo de planeación estratégica, Consejo, (s.f). 
La cadena de valor resalta los procesos estratégicos, enfocados a la creación de valor y relacionamiento con los grupos de interés y el direccionamiento en conjunto del consejo, en el marco de la actividad señalada en la ley.

De la misma manera quedan formalizados los procesos misionales, los cuales además de centrarse en el fundamental, explícitamente enunciado en las normas, habilita la gestión y transferencia de conocimiento, vital para coadyuvar el fomento de la profesión de administrador de empresas. Finalmente, se establecen los procesos que soportarán tanto la gestión misional como la estratégica; estos tienen que ver con los procesos tecnológicos, administrativos -financieros, jurídicos, de gestión de proyectos y de talento humano. Estos últimos son la base para el logro de los objetivos trazados en el periodo 2015 - 2020.

A continuación (Figura 5; Figura 6), se aprecia la articulación de los procesos base para el logro de objetivos desde la óptica de cómo se deben orientar los recursos al interior del Consejo. En detalle, la información se interpreta así:

Figura 5. Articulación de la estrategia.

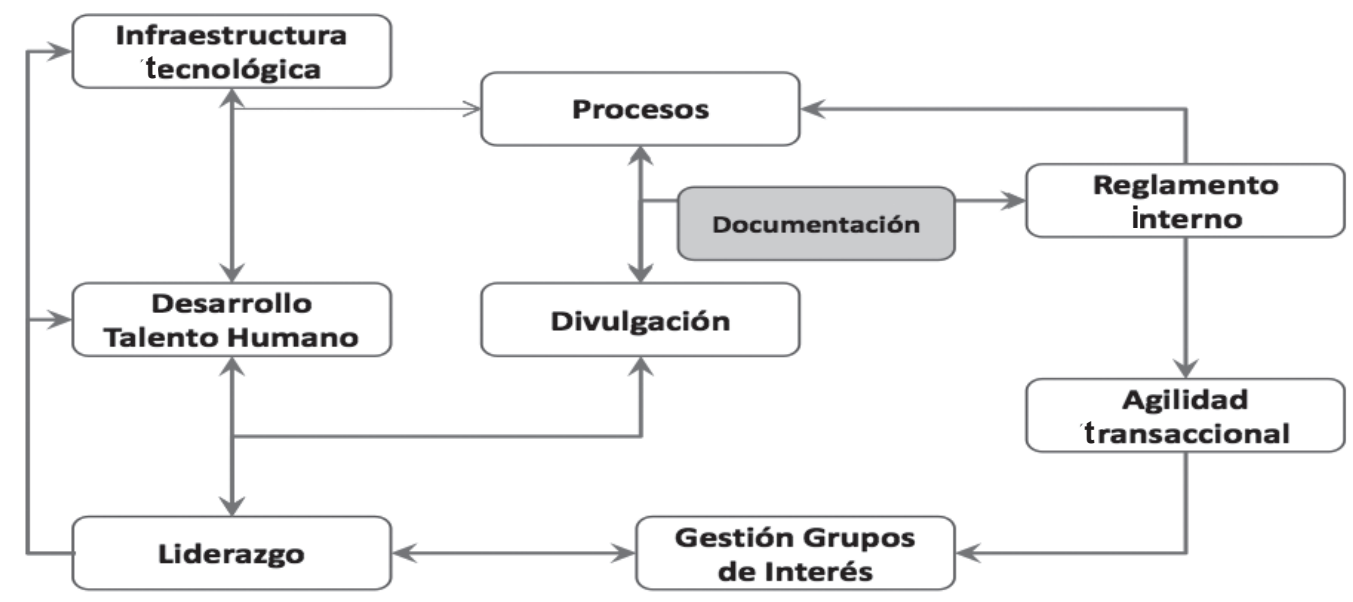

Fuente. Elaborado por el equipo de planeación estratégica, Consejo, (s.f). 
Figura 6. BSC, cuatro perspectivas.

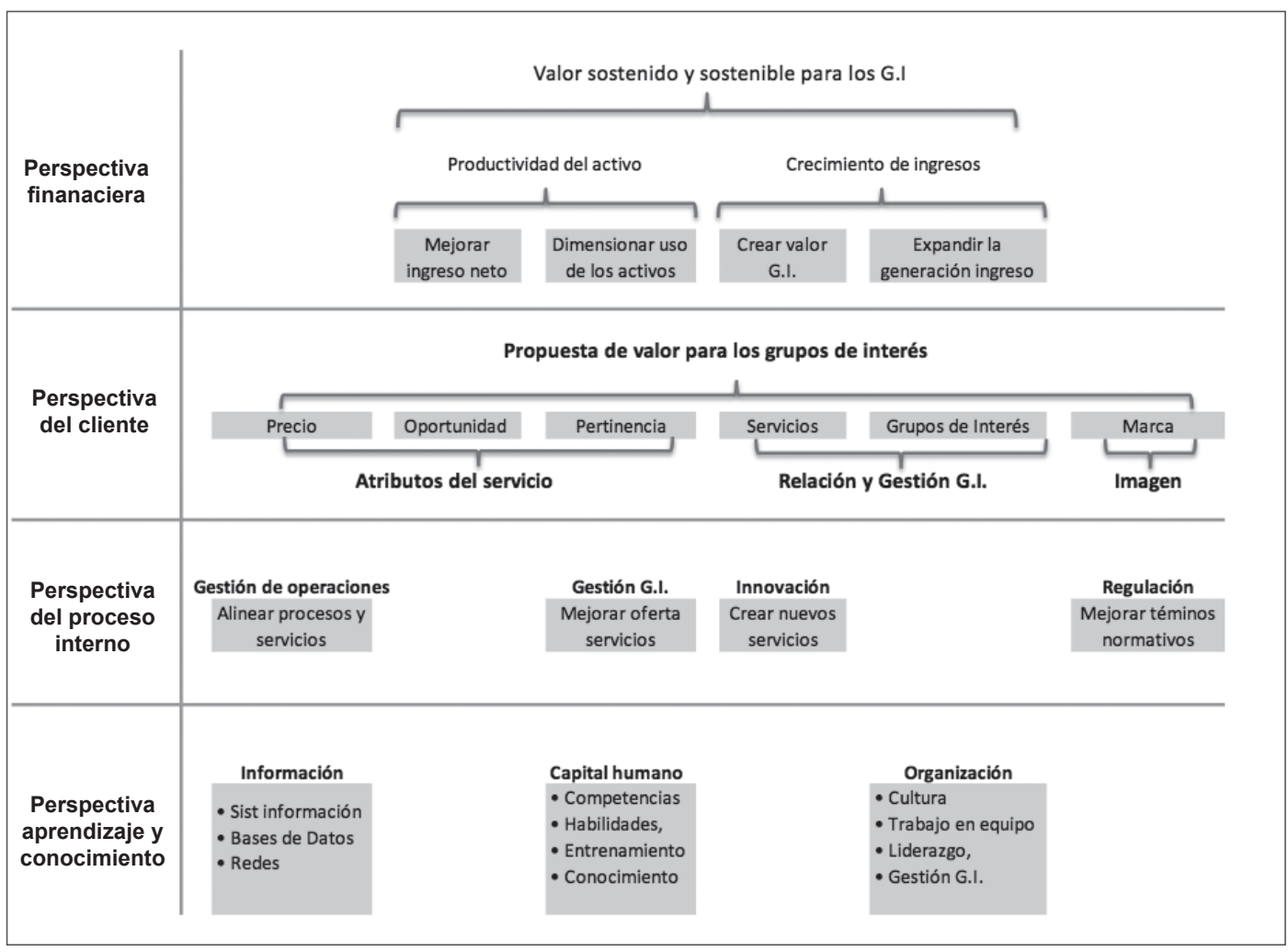

Fuente. Adaptado de Kaplan y Norton; equipo de planeación, Consejo, (s.f).

\section{Fase Il: despliegue del plan de acción}

a implementación del plan estratégico $\checkmark$ formulado o despliegue del plan de acción, consistió en la identificación de los proyectos que permitieran la operacionalización de las líneas estratégicas contempladas en el plan. De esta manera, se realizó una articulación entre los proyectos resultantes con los objetivos del plan, se definieron los cronogramas, indicadores y entregables para el periodo 2015-2020. Igualmente, se redefinieron los procesos correspondientes, articulados con los tradicionalmente administrados en el consejo.

\subsection{Proyectos}

Teniendo como base las líneas estratégicas identificadas en la Fase 1, se agruparon los proyectos representativos de cada línea, el área que liderará los desarrollos, el producto final y el cronograma correspondiente.

De manera general, un proyecto implica una serie de definiciones previas que permitan orientar las acciones en búsqueda del desarrollo de un producto o la potenciación de un servicio, por ello es inherente definir esas definiciones a partir de los siguientes cuestionamientos: ¿Qué? ¿Por qué? ¿Cuándo? ¿Con quién? ¿Para qué? y ¿Cuánto?

Los anteriores cuestionamientos son base esencial para poder emprender la formulación de los proyectos para lo cual el Consejo, previamente debe orientar la dinámica interna para 
llevar a cabo dicha gestión, estandarizando el proceso o método correspondiente.
Se muestran los proyectos que figuran con ocasión de operacionalizar o mejorar el portafolio de servicios (Tabla 5).

Tabla 5. Proyectos asociados con la línea de grupos de interés - portafolio de servicios.

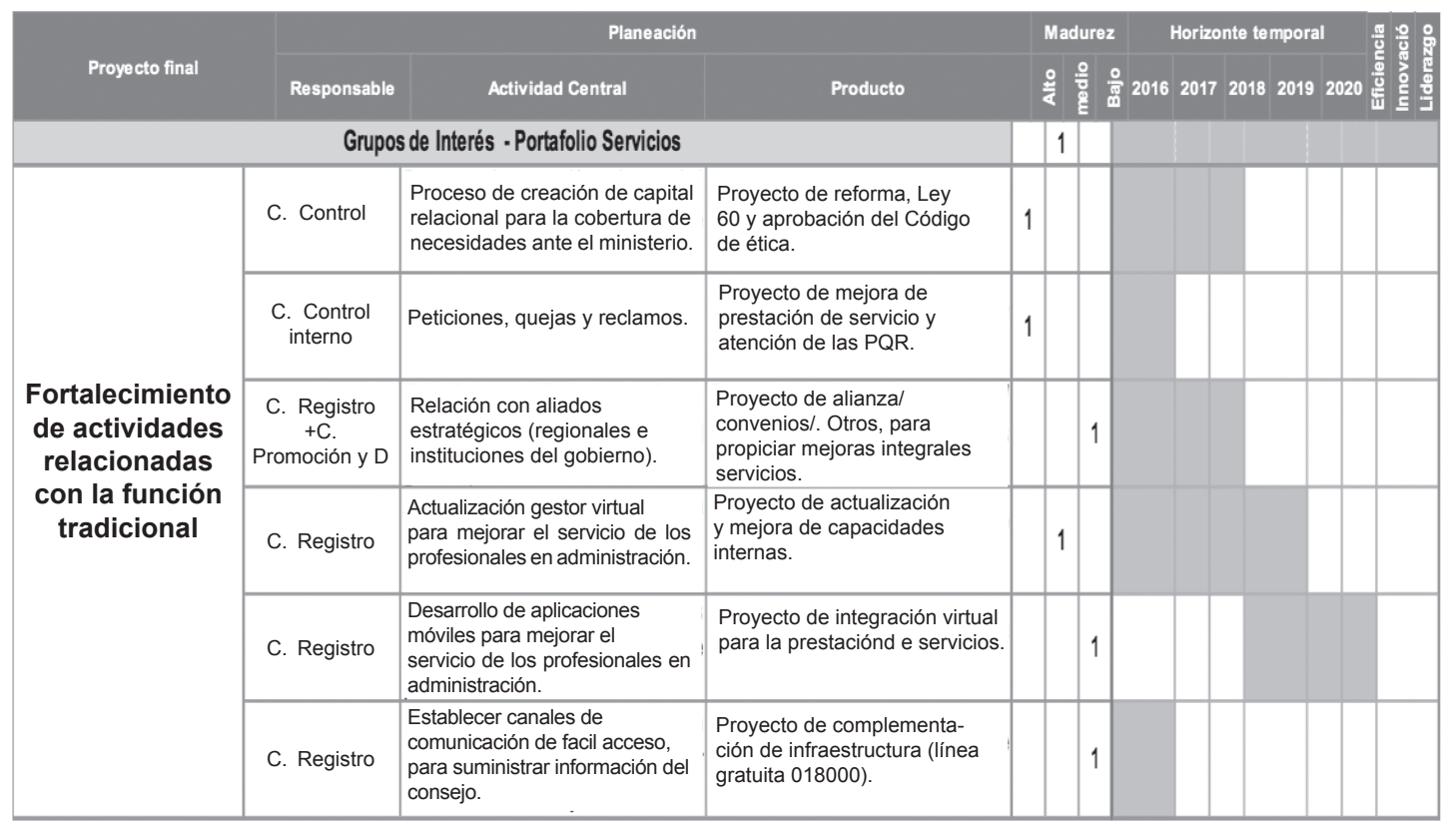

Fuente. Elaboración por parte del equipo de gestión y despliegue de la estrategia, (s.f).

Más adelante (Tabla 6), se muestran los proyectos y actividades enfocadas en la generación de información para el empleo.

Tabla 6. Proyectos asociados con la línea de gestión de grupos de interés - servicios.

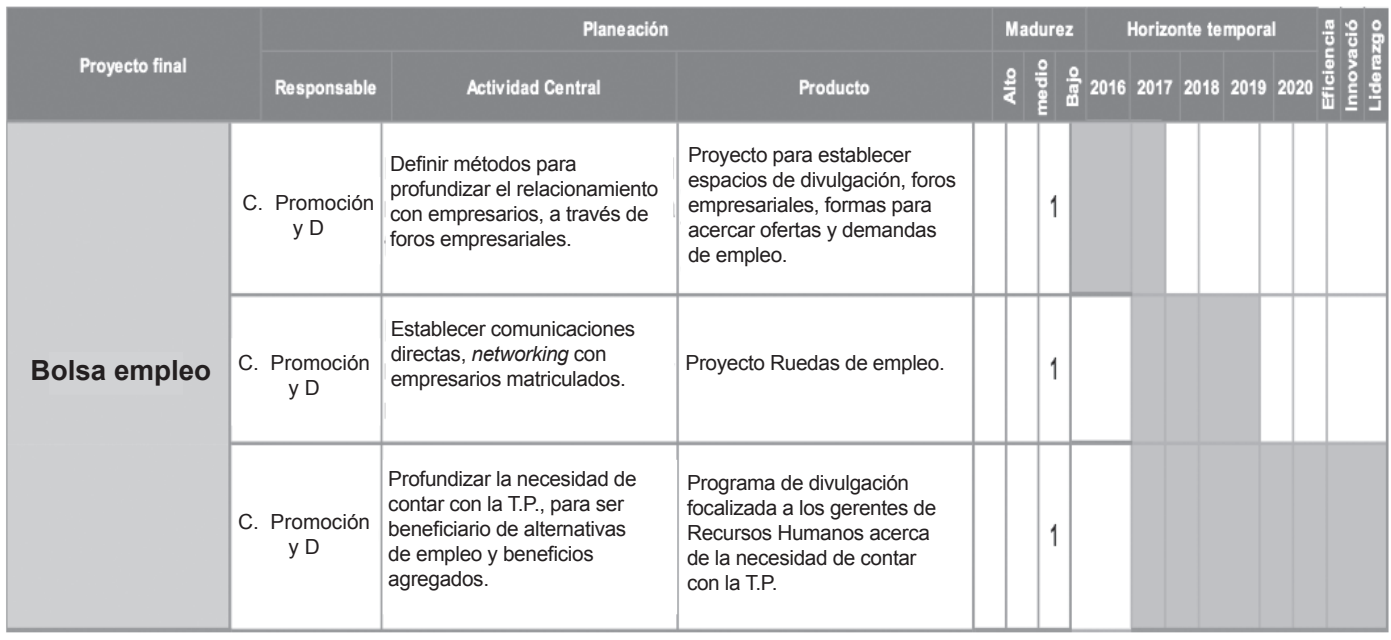

Fuente. Elaboración por parte del equipo de gestión y despliegue de la estrategia, (s.f). 
Se presentan los proyectos y actividades enfocadas en la construcción de capital relacional (Tabla 7).

Tabla 7. Proyectos asociados con la línea de gestión de grupos de interés - capital relacional.

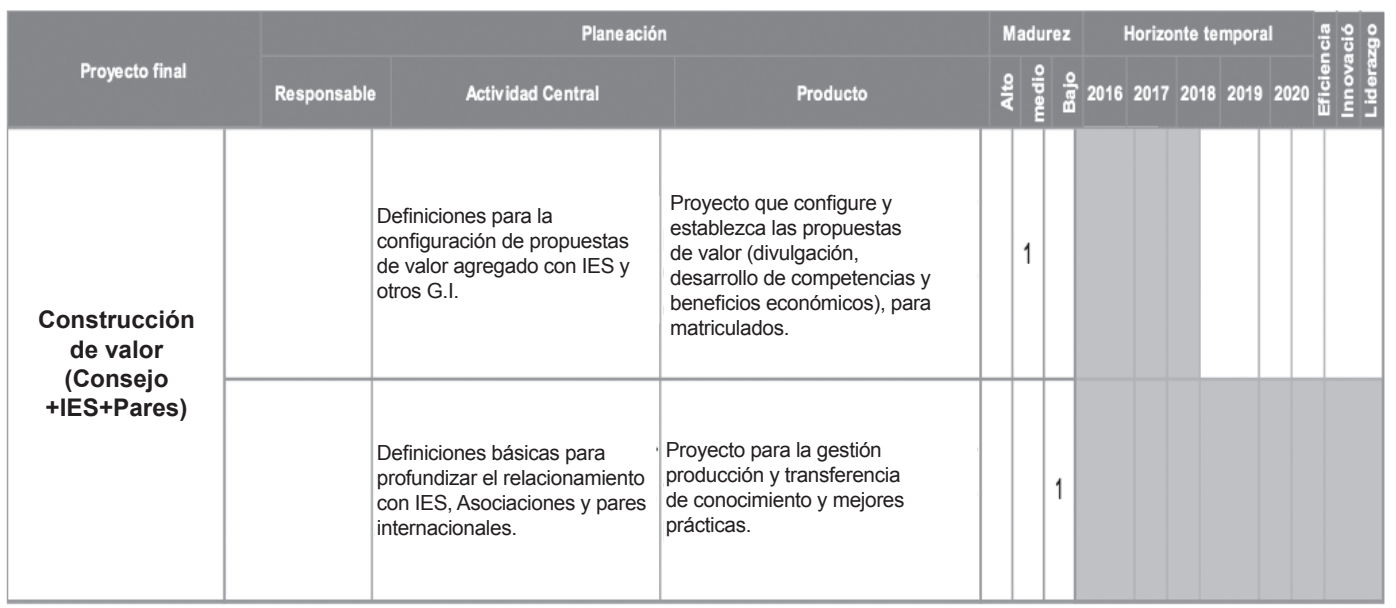

Fuente. Elaboración por parte del equipo de gestión y despliegue de la estrategia, (s.f).

Así, se muestran los proyectos y actividades enfocadas en la línea estratégica de divulgación (Tabla 8). Esta línea se constituye en la respuesta que el consejo deberá dar como complemento a la labor de construcción planteada en la línea estratégica anterior.

Tabla 8. Proyectos asociados con la línea de divulgación.

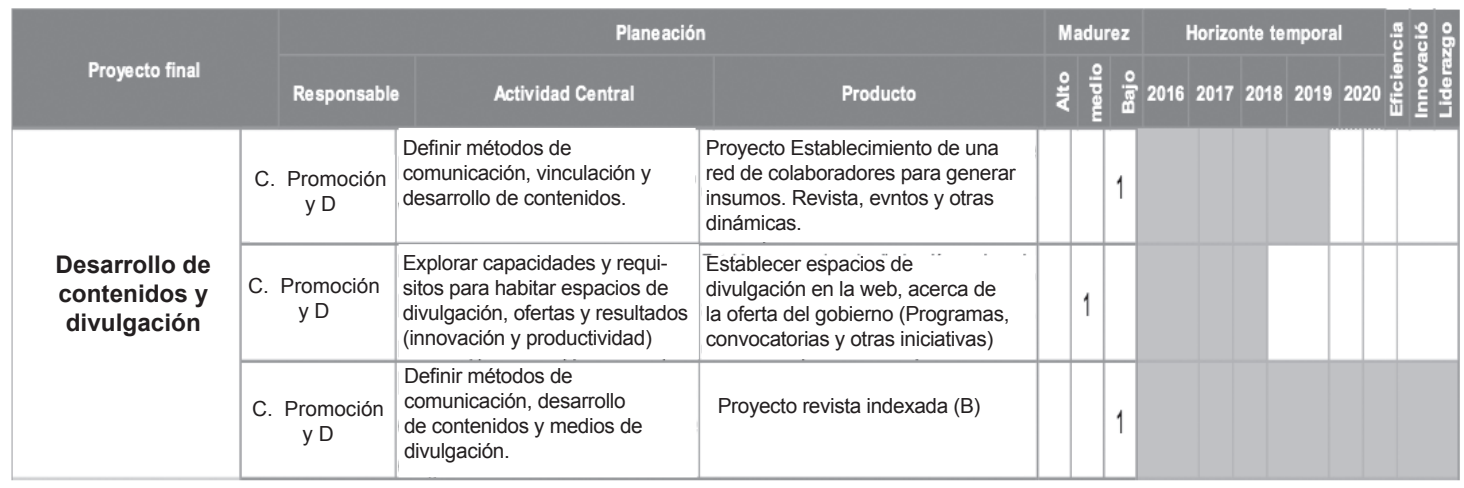

Fuente. Elaboración por parte del equipo de gestión y despliegue de la estrategia, (s.f).

A continuación, se muestran, fundamentalmente, las actividades enfocadas en la línea estratégica de procesos, que se constituye en la articuladora de las anteriores en la medida en que depura los procesos internos para garantizar la respuesta en términos de eficiencia de las labores del consejo (Tabla 9). Implica la mejora de los procesos tradicionales, el levanamiento y mapeo de los procesos emergentes, con ocasión de las actividades y objetivos del plan estratégico, además de la elaboración de mapas y manuales correspondientes. Implica la estandarización de los proyectos de mejora que resulten de la interpretación y análisis de los indicadores correspondientes, y/o informes de control interno. 
Tabla 9. Actividades relacionadas con procesos.

\begin{tabular}{|c|c|c|c|c|c|c|c|c|c|c|c|}
\hline \multirow[b]{2}{*}{ Proyecto final } & \multicolumn{3}{|c|}{ Planeación } & \multicolumn{3}{|c|}{ Madurez } & \multicolumn{5}{|c|}{ Horizonte temporal } \\
\hline & Responsable & Actividad Central & Producto & $\frac{0}{\square}$ & $\begin{array}{l}0 \\
\overline{0} \\
0 \\
\varepsilon\end{array}$ & $\frac{0}{\pi}$ & 2016 & 2017 & 2018 & 2019 & 2020 \\
\hline \multirow{3}{*}{$\begin{array}{l}\text { Adecuación } \\
\text { procesos } \\
\text { internos }\end{array}$} & $\begin{array}{c}\text { C. Control } \\
\text { interno. }\end{array}$ & $\begin{array}{l}\text { Alineación de procesos/ prestación } \\
\text { de servicio en el marco de la ley. }\end{array}$ & $\begin{array}{l}\text { Elaboración de mapas de procesos } \\
\text { tradicionales y emergentes-Políticas } \\
\text { de operación. }\end{array}$ & 1 & & & & & & & \\
\hline & $\begin{array}{l}\text { C. Control } \\
\text { interno. }\end{array}$ & $\begin{array}{l}\text { Alineación de procesos/ prestación } \\
\text { de servicio en el marco de la ley. }\end{array}$ & $\begin{array}{l}\text { Elaboración de manuales; } \\
\text { procedimientos y funciones }\end{array}$ & & 1 & & & & & & \\
\hline & $\begin{array}{l}\text { C. Control } \\
\text { interno. }\end{array}$ & $\begin{array}{l}\text { Alineación de procesos/ prestación } \\
\text { de servicio en el marco de la ley. }\end{array}$ & $\begin{array}{l}\text { Alineación indicadores gestión } \\
\text { (informes/medición y desempeño) }\end{array}$ & & 1 & & & & & & \\
\hline
\end{tabular}

Fuente. Elaboración por parte del equipo de gestión y despliegue de la estrategia, (s.f).

Los proyectos y actividades enfocadas en la línea estratégica de gestión de talento humano que describe los proyectos, programas y actividades que resulten, para mejorar las competencias a los coordinadores y demás colaboradores del Consejo, en el marco de las exigencias, retos y objetivos propuestos en el plan estratégico (Tabla 10).

Tabla 10. Proyectos asociados con gestión de talento humano.

\begin{tabular}{|c|c|c|c|c|c|c|c|c|c|c|}
\hline \multirow[b]{2}{*}{ Proye cto final } & \multicolumn{3}{|c|}{ Planeación } & \multicolumn{2}{|c|}{ Madurez } & \multicolumn{5}{|c|}{ Horizonte temporal } \\
\hline & Responsable & Actividad Central & Producto & $\frac{\circ}{4}$ & $\frac{0}{8}$ & 2016 & 2017 & 2018 & 2019 & 2020 \\
\hline \multirow{5}{*}{$\begin{array}{l}\text { Gestión talento } \\
\text { humano }\end{array}$} & C. Registro & $\begin{array}{l}\text { Elaborar sistema de incentivos/ } \\
\text { metas/indicadores. }\end{array}$ & $\begin{array}{l}\text { Proyecto de formulación de } \\
\text { políticas/programas de bienestar } \\
\text { social. }\end{array}$ & & 1 & & & & & \\
\hline & C. Registro & $\begin{array}{l}\text { Declaración de políticas para la } \\
\text { prestación del servicio. }\end{array}$ & $\begin{array}{l}\text { Proyecto de formulación de } \\
\text { políticas para la gestión del talento } \\
\text { humano. }\end{array}$ & & 1 & & & & & \\
\hline & C. Registro & $\begin{array}{l}\text { Plan de desarrollo de } \\
\text { capacidades, habilidades y } \\
\text { conocimientos. }\end{array}$ & $\begin{array}{l}\text { Proyecto para proveer un programa } \\
\text { de formación y capacidades } \\
\text { estratégicas. }\end{array}$ & & 1 & & & & & \\
\hline & C. Registro & $\begin{array}{l}\text { Declaración de planes y } \\
\text { programas de bienestar. }\end{array}$ & $\begin{array}{l}\text { Elaboración de planes y programas } \\
\text { de bienestar para colaboradores. }\end{array}$ & & 1 & & & & & \\
\hline & C. Registro & $\begin{array}{l}\text { Cumplimiento funciones (Art.9 } \\
\text { de la Ley } 60 \text { de 1981). }\end{array}$ & $\begin{array}{l}\text { Revisión y ajuste del sistema de } \\
\text { gestión y comunicación con el } \\
\text { consejo directivo. }\end{array}$ & 1 & & & & & & \\
\hline
\end{tabular}

Fuente. Elaboración por parte del equipo de gestión y despliegue de la estrategia, (s.f). 


\section{Cadena de valor final y articulación del plan de acción}

\begin{abstract}
sí, se representa la concepción final de la cadena de valor del Consejo y pone de relieve los procesos estratégicos, enfocados a la creación de valor y relacionamiento con los grupos de interés. De la misma manera quedan formalizados los procesos misionales, los cuales además de centrarse en el fundamental, explícitamente enunciado en las normas, habilita la gestión y transferencia de conocimiento, base de todo el proceso para posicionar el
\end{abstract}

consejo en el ámbito de los profesionales y en general grupos de interés de la profesión de administración de empresas. Finalmente, se establecen los procesos que soportarán tanto la gestión misional como la estratégica, estos tienen que ver con los procesos tecnológicos, administrativos-financieros, jurídicos y de talento humano, base para el logro de los objetivos trazados en el periodo 2015-2020 (Figura 7).

Figura 7. Cadena de valor del Consejo

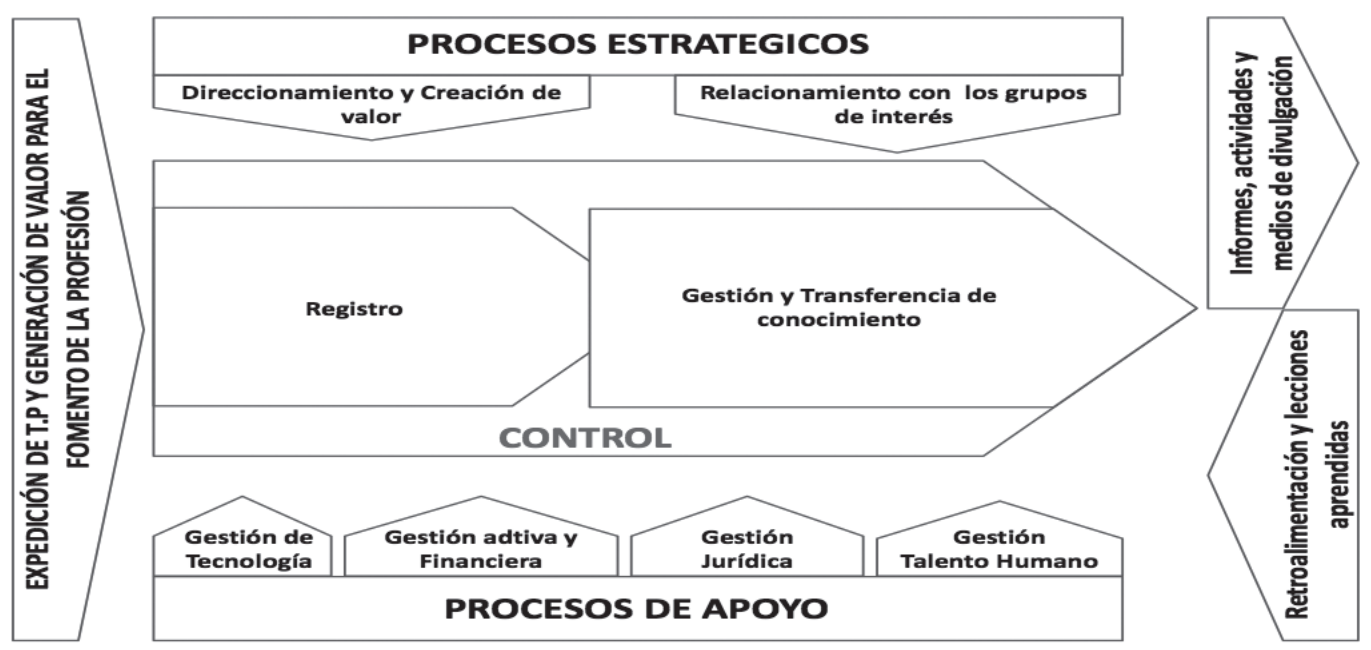

Fuente. Elaboración por parte del equipo de gestión y despliegue de la estrategia, (s.f).

Se aprecia la articulación de los procesos base para el logro de objetivos, desde la óptica de cómo se deben orientar los recursos al interior del consejo. En detalle la figura se interpreta así (Figura 8):

La interacción de la Infraestructura tecnológica combinada con el desarrollo del talento humano; las primeras como soporte y vehículo de las acciones y el segundo como gestor de esas acciones, va a propiciar que mediante la definición de procesos adecuados, fluya la información, divulgación de los hechos cotidianos y los hechos portadores de propuestas de valor -los proyectos desarrollados- para los grupos de interés. Dichos procesos consultan permanentemente el reglamento interno de operación cuyos ajustes y cambios están recogidos oportunamente por los procesos del consejo. El reglamento interno igualmente es 
la base que propicia la claridad en la operación y asegura la agilidad en las transacciones con los usuarios del consejo. En conjunto la agilidad en la demanda de transacciones de los usuarios más los procesos de divulgación y servicios contemplados, en conjunto con la gestión de los grupos de interés, fundamentarán el liderazgo del consejo y en la medida de su evolución acarreará nuevas demandas en las capacidades y competencias que iniciaron la dinámica planteada aquí.

Figura 8. Articulación de la estrategia.

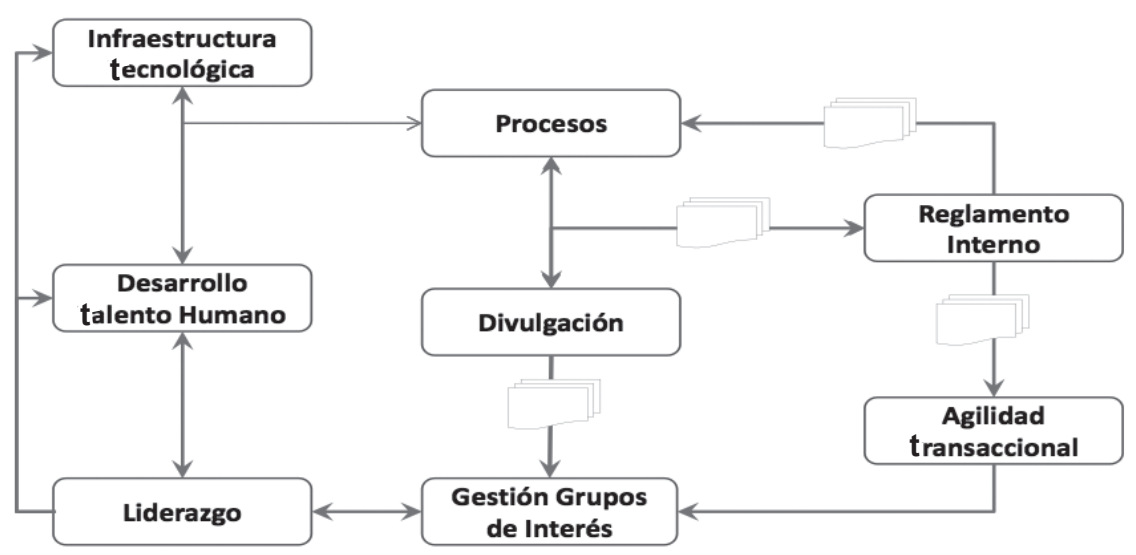

Fuente. Elaboración por parte del equipo de gestión y despliegue de la estrategia, (s.f). 


\section{Propuesta preliminar de indicadores}

Tabla 11. Sostenibilidad financiera

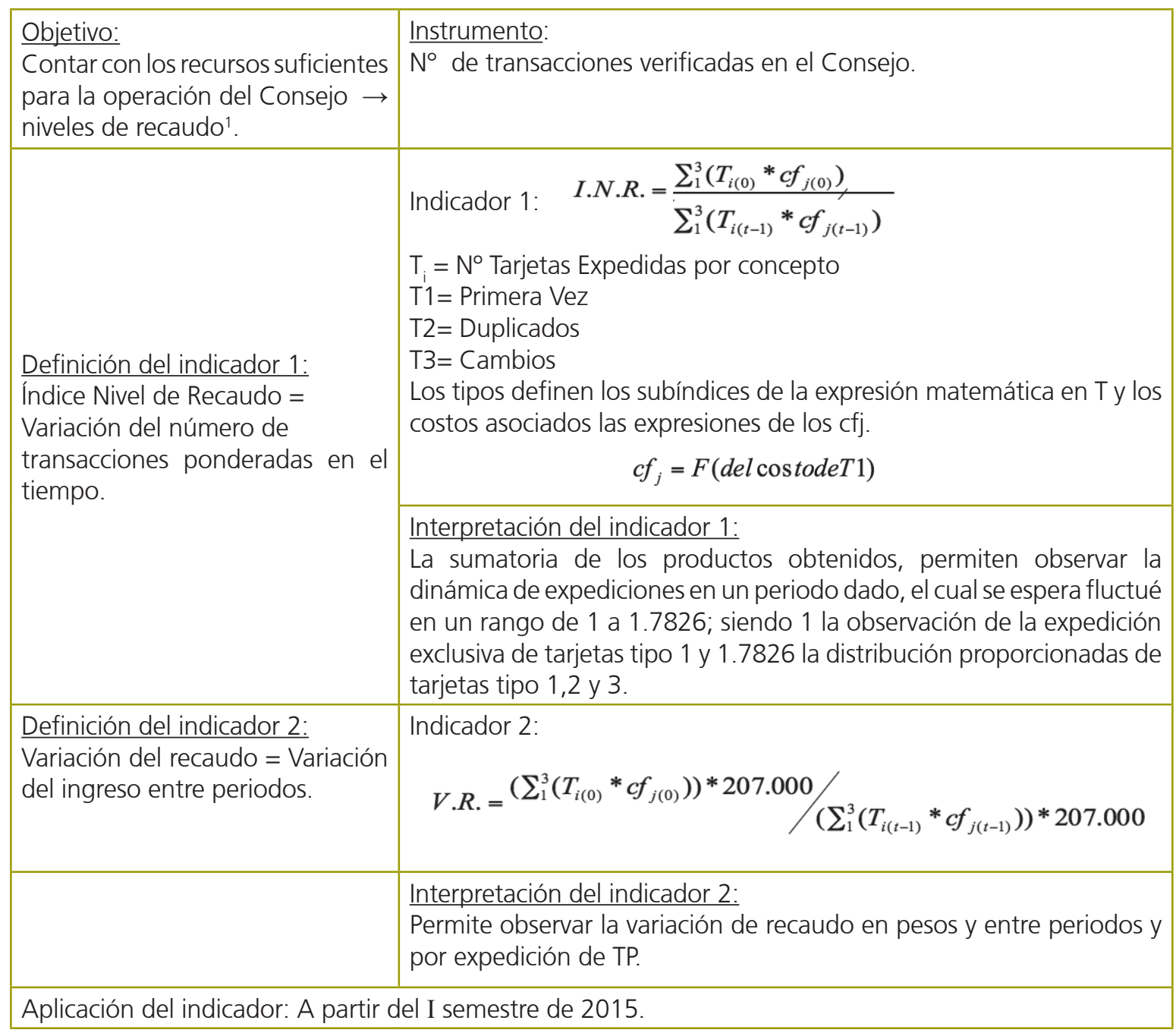

Fuente. Comité estratégico CPAE, (s.f).

\footnotetext{
${ }^{1}$ Niveles de recaudo: se infiere del producto del número de tarjetas expedidas por el costo correspondiente en el año de análisis.
} 
Tabla 12. Infraestructura física

\begin{tabular}{|c|c|}
\hline $\begin{array}{l}\text { Objetivo: gestionar la adquisición } \\
\text { de infraestructura física y de } \\
\text { capital humano adecuados para } \\
\text { el funcionamiento del consejo } \\
\rightarrow \text { Infraestructura adecuada y } \\
\text { suficiente }^{2} \text {. }\end{array}$ & $\begin{array}{l}\text { Instrumento: lista de chequeo predefinida y derivada, inicialmente, } \\
\text { del consenso del comité administrativo }\end{array}$ \\
\hline $\begin{array}{l}\text { Definición del indicador: } \\
\text { confronta el cumplimiento de } \\
\text { la lista de chequeo prevista o } \\
\text { programada, con las ejecuciones } \\
\text { y materialización de las } \\
\text { inversiones y compras realizadas } \\
\text { Indicador: } L c h I=C / P \\
C=N^{\circ} \text { Itemscubiertos } \\
\mathrm{P}=\mathrm{N}^{\circ} \text { Itemsprogramados }\end{array}$ & $\begin{array}{l}\text { Interpretación del indicador: } \\
\text { Si } 1 \text { mostrará la cobertura total de la lista de chequeo y los niveles } \\
\text { superiores o inferiores a 1, indicarán respectivamente, aspectos no } \\
\text { tenidos en cuenta y asumidos o defectos, respecto de la lista de } \\
\text { chequeo elaborada }\end{array}$ \\
\hline
\end{tabular}

Fuente. Comité estratégico CPAE, (s.f).

Tabla 13. Infraestructura tecnológica

Objetivo: disponer de las TIC pertinentes y adecuadas para la prestación eficiente del servicio.

Línea de acción 1: diagnóstico y definición de necesidades.

Instrumento: levantamiento de información Definición del indicador: confronta el cumplimiento de la (lista de necesidades y capacidades requeridas por cada coordinación en el marco de la PE) y elaboración del cronograma correspondiente. La lista derivará inicialmente, del consenso del comité administrativo ${ }^{3}$.

Interpretación del indicador: lista de chequeo prevista o programada, con la inclusión en el proyecto.

Indicador: $L \operatorname{chI}=C / P$

$C=N^{0}$ Items cubiertos

$\mathrm{P}=\mathrm{N}^{\circ}$ Items programados

Si 1 mostrará la cobertura total de la lista de chequeo y los niveles superiores o inferiores a 1 , indicarán respectivamente, aspectos no tenidos en cuenta y asumidos o defectos, respecto de la lista de chequeo elaborada.

2 Adecuado y suficiente, deriva del levantamiento que hará el comité administrativo, en primera instancia, acerca de las necesidades detectadas en ejercicio de las operaciones cotidianas y esperadas - de acuerdo con el PE 2015-2020-. Teniendo como punto de partida, las observaciones acerca de ineficiencias, conflictos, fallas en el clima organizacional, etc.

3 Pertinentes y adecuadas, implica que se correspondan con las necesidades detectadas, que cubran, integren y articulen los desarrollos ya iniciados, y que respondan a las expectativas futuras trazadas en el PE 2015-2020. 
Tabla 13. Infraestructura tecnológica (Continuación)

Línea de acción 2: formulación del proyecto TIC

Instrumento: levantamiento de requeri- Definición del indicador: confronta el cumplimiento de la mientos, línea de acción 1, verificada con lista de chequeo prevista o programada, con la inclusión antelación por el asesor vs los requerimientos en el proyecto.

incorporados en la formulación del proyecto. necesidades previas Periodo de recuperación de la Inversión

Indicador: $\quad \operatorname{LchIT}_{1}=C_{1} / P$

$\mathrm{C}=\mathrm{N}^{\circ}$ Items cubiertos

$\mathrm{P}=\mathrm{N}^{\circ}$ Items programados

Interpretación del indicador:

Si 1 mostrará la cobertura total de la lista de chequeo y los niveles superiores o inferiores a 1, indicarán respectivamente, aspectos no tenidos en cuenta y asumidos o defectos, respecto de la lista de chequeo elaborada.

\section{TIR del proyecto.}

Instrumento: flujos y horizonte de tiempo del proyecto formulado.

Aplicación del indicador: al final de la formulación y evaluación del proyecto - II Semestre de 2015.

Interpretación del indicador:
1 mostrará la renta generada por el
proyecto y validará la fase de desarrollo e
implementación.

Definición del indicador: tasa de retorno, que iguala la inversión con los flujos futuros descontados.

Indicador: $\quad I_{0}=\sum_{1}^{n}\left[F n /(1+\text { tir })^{n}\right]$

$F n=$ Flujos caja netos

$I_{o}=$ Inversión Inicial

Aplicación del indicador: sobre los datos del proyecto formulado, al final de la formulación del mismo - ॥ Semestre de 2015.

\section{Cumplimiento del crono establecido con seguimiento mensual.}

Instrumento: diagrama de Gantt o similar, en donde se consigna: las fechas de inicio y fin de la formulación y evaluación, los actores del proyecto, los ítems del proyecto -1 aspectos legales, 2 de requerimientos de los grupos de interés, 3 de requerimientos físicos, humanos y tecnológicos, 4 proyección de flujos del proyecto y 5 situaciones generadoras de externalidades del proyecto-, aspectos inherentes a la evaluación del proyecto.

Interpretación del indicador: Si 1, mostrará la ejecución en los términos planteados al inicio de la formulación del proyecto y los niveles superiores o inferiores a 1, indicarán respectivamente, eficiencia o retrasos en la formulación del proyecto.
Definición del indicador: Indicador de cumplimiento $=$ actividades ejecutadas / actividades programadas. (Verifica desfases y costos del proyecto)

I.C. $=A E{ }_{A P}$

$A E=$ Actividades Ejecutadas

$A P=$ Actividades Programadas

Aplicación del Indicador: a final del II Semestre de 2015 
Tabla 13. Infraestructura tecnológica (Continuación)

\begin{tabular}{|c|c|}
\hline \multicolumn{2}{|c|}{ Línea de acción 3: Implementación y puesta en operación - Proyecto TIC } \\
\hline \multicolumn{2}{|c|}{ 1. Cobertura de la lista de requerimientos y necesidades previas } \\
\hline $\begin{array}{l}\text { Instrumento: Levantamiento de } \\
\text { requerimientos Línea de acción 1, } \\
\text { vs requerimientos satisfechos en la } \\
\text { implementación. }\end{array}$ & $\begin{array}{l}\text { Definición del indicador: confronta el cumplimiento de la } \\
\text { lista de chequeo prevista o programada, con la inclusión } \\
\text { en el proyecto en operación } \\
\text { Indicador } L_{c h I T_{2}=C_{2} / P} \\
C_{2}=\mathrm{N}^{\circ} \text { Items cubiertos } \\
P=\mathrm{N}^{\circ} \text { Items programados }\end{array}$ \\
\hline $\begin{array}{l}\text { Interpretación del indicador: Si 1, mostrará } \\
\text { la cobertura total de la lista de chequeo y los } \\
\text { niveles superiores o inferiores a 1, indicarán } \\
\text { respectivamente, los aspectos no tenidos en } \\
\text { cuenta al inicio y contemplados en la fase de } \\
\text { implementación del proyecto o los aspectos } \\
\text { dejados de lado en la implementación del } \\
\text { mismo. }\end{array}$ & $\begin{array}{l}\text { Aplicación del Indicador: Al final de la fase de imple- } \\
\text { mentación del proyecto - II Semestre de } 2016\end{array}$ \\
\hline \multicolumn{2}{|l|}{ 2. Monitoreo - TIR del proyecto } \\
\hline $\begin{array}{l}\text { Instrumento: flujos generados vs flujos } \\
\text { proyectados. }\end{array}$ & $\begin{array}{l}\text { Definición del indicador: recálculo de la tir, ajustada con las } \\
\text { variaciones observadas en los flujos ejecutados. } \\
\text { Indicador: } I_{0}=\sum_{1}^{n}\left[F n /(1+\text { tir })^{n}\right] \\
\begin{array}{l}F n=\text { Flujos de caja netos ajustados } \\
I_{o}=\text { Inversión inicial }\end{array}\end{array}$ \\
\hline $\begin{array}{l}\text { Interpretación del indicador: } \\
\text { Muestra la variación en la tasa de renta del } \\
\text { proyecto versus los ajustes verificados en la } \\
\text { ejecución correspondiente. }\end{array}$ & Aplicación del indicador: a partir del II Semestre de 2016. \\
\hline \multicolumn{2}{|c|}{$\begin{array}{l}\text { 3. Verificación de la relación costo efectivo del proyecto (costos asumidos en la actualidad vs } \\
\text { costos con proyecto. }\end{array}$} \\
\hline \multicolumn{2}{|c|}{$\begin{array}{l}\text { a. Comportamiento del número de reprocesos y costos asociados. } \\
\text { b. Tiempos de respuesta a los usuarios y demás grupos de interés y cálculo de costos asociados. } \\
\text { c. Nivel de satisfacción del Inventario de necesidades por grupos de interés. } \\
\text { d. Dinámica del banco de proyectos. } \\
\text { e. Comportamiento del ingreso. } \\
\text { f. Etc. }\end{array}$} \\
\hline
\end{tabular}

Fuente. Comité estratégico CPAE, (s.f). 
Tabla 14. Gestión grupos de interés

Objetivo: fortalecer relaciones con grupos de interés generando sinergias para la satisfacción de expectativas conjuntas.

\section{Línea 1 identificar: priorizar y convocar a los Grupos de interés.}

Instrumento: Levantamiento de información (lista Definición del indicador: indicador de cobertura = de los grupos de interés; directos e indirectos) y $\mathrm{N}^{\circ} \mathrm{Gl}$ prospectados $/ \mathrm{N}^{\circ} \mathrm{Gl}$ estudiados.

elaboración del cronograma respectivo

- Definición de criterios de priorización (análisis de actores - MML).

- Gestión de los G.I (manual de Foretica).

- Consenso Respecto de las necesidades y GIprs $=$ Gl prospectados requerimientos observados

Interpretación del indicador:

A partir del uso de una matriz multicriterio establecer la prioridad, oportunidad y pertinencia de los servicios estructurados en el portafolio de servicios y definir la oferta y acciones conducentes a las metas y objetivos previstos, señalando el \% de los grupos de interés seleccionado y los servicios a desarrollar.

\section{Línea $\mathbf{2}$ identificar: definición del portafolio de servicios}

Instrumento: previa la definición y clasificación de los grupos de interés por niveles de prioridad ${ }^{4}$ para el consejo, configurar un portafolio de servicios, que oriente y direccione la labor del consejo en el marco del PE 2015 - 2020, previa elaboración del crono respectivo.
Definición del indicador: indicador de cumplimiento por nivel de prioridad = Ofertas estructuradas y ejecutadas vs Ofertas estudiadas y programadas.

Indicador:

$$
I C n p=O e j / O p r
$$

$O e j=$ Ofertas Crono ejecutado

$O_{p r}=$ Ofertas Crono Programado

Aplicación del Indicador: durante el II semestre de

Se verificara por cada ítem del crono establecido 2015.

el nivel de cumplimiento de las actividades, explicando las desviaciones y el impacto esperado en la actividad final.

Línea 3 identificar: desarrollo y monitoreo de valores agregados con énfasis en la investigación Instrumento: Seguimiento a la prestación de Definición del indicador: Indicador de comportaservicios y consecución de valor agregado para el miento por grupo de interés = variación de consejo, derivado de las definiciones de la línea 2 y aceptación y profundización de servicios.

en el marco del PE 2015 - 2020.
$I C G I_{(i)}=$ Indicadores Comportamiento Grupo Interés $S P_{(i)}=$ Servicios Prestados a cada G.I.

$\mathrm{Spr}_{(i)}=$ Servicios Previstos a cada G.I.

\footnotetext{
${ }^{4}$ La prioridad deriva de la necesidad testeada para mitigar riesgos y aprovechar oportunidades, con cada
} uno de los grupos de interés, directos o indirectos, del Consejo. 
Interpretación del indicador:

Se verificara, por cada grupo de interés, el nivel de aceptación y profundización de los servicios ofrecidos y la demanda efectiva observada, analizando del indicador, el nivel de profundidad alcanzado ${ }^{5}$, de acuerdo con las metas y objetivos del consejo.

Indicador 2: verificación del nivel de profundización Interpretación del indicador:

del servicio por grupo de interés (encuesta actual /

encuesta anterior).

$$
N S n_{G I}=E_{T 0} / E_{T-1}
$$

$N S n_{G I}=$ Nivel de profundización en el servicio

Se verificara por cada grupo de interés, el nivel de profundización (cobertura del portafolio ofrecido) y la contribución a las metas y objetivos del Consejo.

Aplicación del Indicador: a partir del II semestre de 2015

$E_{T O}=$ Verificación de cobertura en el presente

$E_{T-1}=$ Verificación de cobertura en el pasado

Fuente. Comité estratégico CPAE, (s.f).

Tabla 15. Divulgación

\begin{tabular}{|c|c|}
\hline \multicolumn{2}{|c|}{ Objetivo: posicionar la labor del Consejo, frente a los grupos de interés directos e indirectos. } \\
\hline \multicolumn{2}{|c|}{ Línea 1: habilitación de canales para divulgar las actividades del Consejo. } \\
\hline $\begin{array}{l}\text { Instrumento: monitoreo de información, respecto } \\
\text { de la penetración y dinámica con los Gl }\end{array}$ & $\begin{array}{l}\text { Definición del indicador: Indicador de cumplimiento= } \\
\text { Canales intı } \\
\qquad C=X_{C I} / Z_{C P} \text { les previstos). } \\
\text { Indicador: } \\
X_{C I}=\text { Canales intervenidos } \\
Z_{C P}=\text { Canales previsto }\end{array}$ \\
\hline $\begin{array}{l}\text { Interpretación del indicador: } \\
\text { Muestra la dinámica y gestión de penetración de } \\
\text { la actividad del consejo con los Gl, explicando las } \\
\text { desviaciones y el impacto esperado en la actividad } \\
\text { final. }\end{array}$ & $\frac{\text { Aplicación del Indicador: durante el II semestre de }}{2015 .}$ \\
\hline \multicolumn{2}{|c|}{ Línea 2: métodos de difusión; objetivo, valor y necesidad contar con la tarjeta profesional. } \\
\hline $\begin{array}{l}\text { Instrumento: procesos y medios de divulgación para } \\
\text { incrementar la cobertura Informativa a los grupos } \\
\text { de interés, en particular con los profesionales } \\
\text { de Administración de Empresas y similares, } \\
\text { contemplados en la ley. }\end{array}$ & 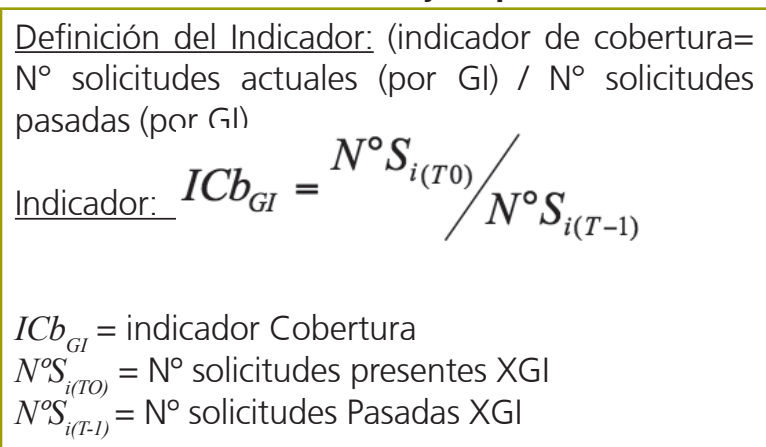 \\
\hline
\end{tabular}

${ }^{5}$ Nivel de profundidad, entendido como la pendiente y dirección de la curva de tendencia observada. 


\section{Tabla 15. Divulgación (Continuación)}

\begin{tabular}{|c|c|}
\hline $\begin{array}{l}\text { Interpretación del indicador: } \\
\text { Muestra la dinámica y gestión de penetración de } \\
\text { la actividad del Consejo con cada uno de los Gl, } \\
\text { explicando las desviaciones y el impacto esperado } \\
\text { en la actividad final }\end{array}$ & $\frac{\text { Aplicación del Indicador: durante el II semestre de }}{2015 .}$ \\
\hline \multicolumn{2}{|c|}{ Línea 3: Dinámicas para la profundización de la presencia del Consejo. } \\
\hline $\begin{array}{l}\text { Instrumento: monitoreo de la gestión y prestación } \\
\text { de servicios por canal y grupo de interés. }\end{array}$ & 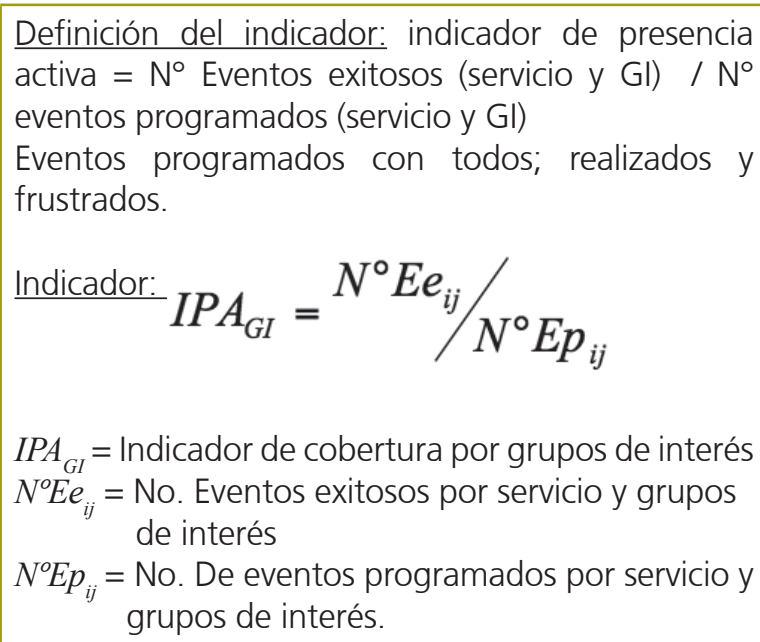 \\
\hline $\begin{array}{l}\text { Interpretación del indicador: } \\
\text { Muestra la dinámica y gestión de penetración de } \\
\text { la actividad del consejo con cada uno de los Gl, } \\
\text { explicando las desviaciones y el impacto esperado } \\
\text { en la actividad final }\end{array}$ & Aplicación del Indicador: durante el II semestre de \\
\hline
\end{tabular}

Fuente. Comité estratégico CPAE, (s.f). 
Tabla 16. Reglamentación interna

\begin{tabular}{|c|c|}
\hline \multicolumn{2}{|c|}{ Objetivo: dar cumplimiento a los mandatos legales que regulan la actividad del Consejo. } \\
\hline \multicolumn{2}{|c|}{ Línea 1: código de ética y ampliación de la raíz en la ley (Sentencia). } \\
\hline $\begin{array}{l}\text { Instrumento: gestión y seguimiento al proceso, que } \\
\text { implique finalmente la publicación de la ley en el } \\
\text { diario oficial. }\end{array}$ & $\begin{array}{l}\text { Definición del indicador: indicador de cumplimiento= } \\
\text { Cronograma ejecutado / Cronograma previsto } \\
\text { Indicador: } I C=C e j / \mathrm{Cpr} \\
C_{e j}=\text { Crono ejecutado } \\
C_{p r}=\text { Crono previsto }\end{array}$ \\
\hline $\begin{array}{l}\text { Interpretación del indicador: } \\
\text { A partir de la planeación prevista para el logro de la } \\
\text { meta y el cronograma correspondiente, verificar el } \\
\text { nivel de cumplimiento, en términos de tiempo, para } \\
\text { el logro de la meta prevista. }\end{array}$ & Aplicación del indicador: a partir I semestre de 2015. \\
\hline \multicolumn{2}{|c|}{ Línea 2: mantener la reglamentación interna actualizada, de acuerdo con los cambios normativos. } \\
\hline $\begin{array}{l}\text { Instrumento: medios y herramientas para la actua- } \\
\text { lización y divulgación de la implicación de las nuevas } \\
\text { normas, en el ámbito y actividad del consejo. }\end{array}$ & $\begin{array}{l}\text { Definición delindicador: indicador decumplimiento= } \\
\text { Fecha de la actualización, implementación y divul- } \\
\text { gación respectivas vs Fecha promulgación de la } \\
\text { norma. } \\
\text { Indicador: } I C=F(a, i, d)-F n \\
\begin{array}{r}F(a, i, d)=\text { Fechas de actualización, implementación } \\
\text { y divulgación }\end{array} \\
F n=\text { Fecha de expedición de la norma }\end{array}$ \\
\hline $\begin{array}{l}\text { Interpretación del indicador: } \\
\text { Corresponde al seguimiento de las actividades de } \\
\text { actualización, implementación y divulgación de las } \\
\text { normas expedidas, bien sea en el ámbito externo } \\
\text { (leyes, decretos, acuerdos etc.) o interno (políticas, } \\
\text { resoluciones, acuerdos del consejo o similares). El } \\
\text { indicador implica la discriminación del rango especi- } \\
\text { ficado como (a,i,d) y en el caso de la divulgación, } \\
\text { contempla la capacitación y empoderamiento, si } \\
\text { hay lugar a ello. }\end{array}$ & Aplicación del Indicador: a partir I semestre de 2015. \\
\hline
\end{tabular}

Fuente. Comité estratégico CPAE, (s.f). 
Tabla 17. Procesos

Objetivo: Contar con procesos óptimos y agiles, que cumplan con las necesidades del Consejo.

Línea 1: optimizar procesos existentes

Instrumento: Elaborar un inventario de procesos que ameriten mejora y den lugar a proyectos priorizados de mejoramiento en el Consejo.

Interpretación del indicador:

A partir del inventario sobre áreas y procesos críticos, elaborar los proyectos de mejora, con sus respectivos cronogramas, con el fin de cumplir con el objetivo previsto y generando información valiosa para el proyecto de infraestructura tecnológica. El indicador por proyecto indicará el grado de cumplimiento del cronograma previsto.

\section{Línea 2: identificar y caracterizar procesos necesarios para cumplir objetivos estratégicos}

Instrumento: mediante el uso de herramientas metodológicas, acopiar los datos necesarios que permitan identificar los ajustes, modificaciones o apertura de nuevos procesos, con ocasión del despliegue de actividades asociadas con la PE 2015-2020.

Interpretación del indicador:

Con base en una lista de chequeo derivada de la línea 1 y de los requerimientos emergentes de la PE 2015 - 2020, además de la elaboración del cronograma correspondiente, verificar el avance en materia de adopción e implementación de los nuevos requerimientos en los procesos del consejo.
Definición del indicador: indicador de cumplimiento por proyecto de mejora = Cronograma ejecutado / Cronograma previsto

Indicador: $I C p y_{i}=\mathrm{Cej}_{i} / \mathrm{Cpr}_{i}$

$\mathrm{Cej}_{i}=$ Cronograma ejecutado del proyecto

$\mathrm{Cpr}_{i}=$ Cronograma previsto del proyecto

Aplicación del Indicador: a partir I semestre de 2015.

Línea 3: Articular los procesos del consejo, en un cuerpo integral y alineado con los grupos de interés

Instrumento: Datos e información provenientes de la línea 1 y 2, para verificar la alineación y articulación de los procesos del consejo, con los requerimientos emergentes de la implementación del PE 2015 - 2020.

Interpretación del indicador:

Muestra el grado de cumplimiento a partir de los ítems ejecutados respecto de los ítems previstos como necesarios y suficientes para la excelente prestación de servicios ofrecidos por el consejo.

Fuente. Comité estratégico CPAE, (s.f).
Definición del indicador: indicador de Ajuste procesos = Identificación de nuevas actividades, procedimientos y acciones / adopción e implementación en los procesos del consejo.

Indicador: $I A p r=I D(a, p, a c \ldots n)-A I p r$

ID $(a, p, a c, . . n)=$ Identificación de nuevas características en procesos

AIpr = Adopción e implementación de procesos

Aplicación del Indicador: a partir I semestre de 2015. indicador de alineación y ajuste = Ítems adoptados, ajustados y emergentes en los procesos del consejo vs lista de chequeo pre-vista con anterioridad.

Indicador: $I A a j=$ Liej $/$ LChpr

Liej $=$ Lista de ítems ejecutados

$L C h p r=$ Lista de chequeo prevista

Aplicación del Indicador: A partir I semestre de 2015 
Tabla 18. Gestión de talento humano

\begin{tabular}{|c|c|}
\hline \multicolumn{2}{|c|}{ Objetivo: contar con el recurso humano idóneo, para el cumplimiento de las fur } \\
\hline \multicolumn{2}{|c|}{ Línea 1: fomentar y formar la capacidad individual de los trabajadores } \\
\hline $\begin{array}{l}\text { Instrumento: A partir del inventario de capital } \\
\text { humano y de los recursos y capacidades existentes y } \\
\text { por adoptar en el consejo, Elaborar un proyecto de } \\
\text { capacitación y desarrollo de talento humano, que } \\
\text { garantice el óptimo funcionamiento de las labores del } \\
\text { consejo. }\end{array}$ & $\begin{array}{l}\text { Definición del indicador: Indicador de cumplimiento } \\
\text { desarrollo de talento humano = Proyecto ejecutado / } \\
\text { Proyecto formulado } \\
\text { Indicador: } I C D T H=\text { Pyej/ Pyf } \\
\text { Pyej = Proyecto ejecutado } \\
\text { Pyf = Proyecto formulado }\end{array}$ \\
\hline $\begin{array}{l}\text { Interpretación del indicador: } \\
\text { A partir de la formulación del proyecto de desarrollo } \\
\text { de talento humano en el consejo y de la identificación } \\
\text { de los programas y acciones, consignados en un } \\
\text { cronograma, de manera periódica monitorear el } \\
\text { cumplimiento correspondiente, dejando evidencia en } \\
\text { el indicador propuesto. }\end{array}$ & Aplicación del Indicador: a partir I semestre de 2015. \\
\hline \multicolumn{2}{|l|}{ Línea 2: elaborar planes y programas de bienestar } \\
\hline $\begin{array}{l}\text { Instrumento: generar espacios, instrumentos } \\
\text { y ambiente propicio para el despliegue de las } \\
\text { capacidades de losfuncionarios del consejo, orientados } \\
\text { a la potenciación de capacidades, la generación de } \\
\text { iniciativas y formulación y desarrollo de propuestas } \\
\text { innovadoras, que generen compromiso y beneficios } \\
\text { comunes, en el marco de la PE 2015-2020. }\end{array}$ & $\begin{array}{l}\text { Definición del indicador: indicador de Bienestar }= \\
\text { Observación de los } \mathrm{X}(\mathrm{i}, \mathrm{j}, \mathrm{k}) \text { respecto del promedio. } \\
\text { Indicador: } I B=\left(X_{i}>\bar{X}_{i}\right) / \sum i \\
\text { Superior al } 70 \% \\
X i=X(a+b+c)=\text { resultado ponderado individual } \\
\text { - } a=\text { iniciativa ponderada } \\
\text { - } b=\text { Compromiso ponderado } \\
\text { - } c=\text { Formulación y desarrollo proyectos ponderado }\end{array}$ \\
\hline $\begin{array}{l}\text { Interpretación del indicador: } \\
\text { A partir de los resultados individuales ponderados } \\
\text { respecto de la contribución en número de iniciativas, } \\
\text { ponderadas por } 20 \% \text {; compromiso, ponderado } \\
\text { con } 30 \% \text { y formulación y desarrollo de proyectos, } \\
\text { ponderado con } 50 \% \text {, se establecen los resultados } \\
\text { individuales, los cuales se observaran respecto del } \\
\text { promedio obtenido, verificando resultados no inferiores } \\
\text { al } 70 \% \text {, para calificar el bienestar como muy bueno en } \\
\text { el consejo. }\end{array}$ & Aplicación del Indicador: A partir I semestre de 2015. \\
\hline \multicolumn{2}{|l|}{ Línea 3: Elaborar plan de Incentivos } \\
\hline $\begin{array}{l}\text { Instrumento: Datos e información provenientes de la } \\
\text { línea } 1 \text { y } 2 \text { para diseñar y aplicar el plan de incentivos. }\end{array}$ & $\begin{array}{l}\text { Definición del indicador: Indicador de incentivos = } \\
\text { Brecha observada / Brecha prevista. }\end{array}$ \\
\hline & $\begin{array}{l}\text { Indicador: } \quad I i=B o b s / B p r \\
\text { Bobs = Información obtenida de la evaluación del } \\
\text { indicador de bienestar } \\
\text { Bpr = Información obtenida del inventario de talento } \\
\text { humano. }\end{array}$ \\
\hline $\begin{array}{l}\text { Interpretación del indicador: } \\
\text { Muestra el grado de cerramiento de la brecha } \\
\text { observada por cada individuo, como insumo del } \\
\text { diseño y revisión del plan de incentivos. }\end{array}$ & Aplicación del Indicador: A partir I semestre de 2015. \\
\hline
\end{tabular}

Fuente. Comité estratégico CPAE, (s.f). 


\section{ANEXO 1 \\ TEACHING NOTES \\ -GUÍA PARA EL FACILITADOR O LA FACILITADORA DEL CASO-}

\section{Objetivos del Caso}

1.1 Mostrar didácticamente al lector la manera en que se realiza un análisis MICMAC como método en el ámbito de la planeación estratégica.

1.2 Desglosar las herramientas utilizadas en un diagnóstico y en el despliegue de un plan estratégico.

1.3 Estudiar cómo se redactan líneas y proyectos estratégicos.

\section{Aspectos a resolver}

2.1 Qué otro análisis realizaría para el MICMAC.

2.2 Frente a los resultados del MICMAC, presente otras líneas de acción.

2.3 Ingrese a la página Web de CPAE y comente con sus compañeros frente a los proyectos estratégicos cuales se han realizado y cuáles no. ¿Cuáles faltarían?

2.4 Haga un análisis sobre los indicadores.

\section{Metodología sugerida para trabajar el caso con un grupo de estudiantes}

3.1 En la primera sesión -30 minutos-:

- $\quad$ Si es un grupo de 28 personas, subdividirlo en siete grupos de cuatro personas -si es de más personas o menos, se recomienda que los subgrupos sean máximo de cuatro personas-

- Entregar al grupo el caso, sin las teaching notes, para que cada subgrupo estudie el caso y traiga resueltos los tres aspectos a resolver.

- Leer el caso en voz alta

- Dar instrucción que para la próxima sesión los estudiantes por subgrupo traigan resueltos los tres aspectos.

3.2 Segunda sesión -dos horas-:

- Cada grupo lee las soluciones al primer aspecto a resolver -una hora-.

- El facilitador apunta en sitio visible las respuestas de cada subgrupo y las pone en discusión -una hora-.

3.3 Tercera sesión -dos horas y media-:

- Cada grupo lee las respuestas al segundo y tercer aspecto -una hora-.

- El facilitador apunta en sitio visible las respuestas de cada subgrupo y las pone en discusión -una hora-.

- $\quad$ El facilitador presenta conclusiones del caso -30 minutos-.

3.4 Cuarta sesión: - dos horas-

- Cada grupo lee las respuestas al cuarto aspecto a resolver (1 hora).

- El facilitador apunta en sitio visible las respuestas de cada subgrupo y las pone en discusión y presenta conclusiones del caso -una hora-. 


\section{Referencias bibliográficas}

David, F. R. (2003). Conceptos de Administración Estratégica. Editorial PEARSON, Prentice Hall.

Drucker, P. (2002). La gerencia de la sociedad futura. Recuperado de: http://www.faecc. recabeitia.com.ar/2012/dege-2\%20jueves/ lecturas/drucker, \%20peter\%20-\%20la\%20 gerencia\%20en\%20la\%20sociedad $\% 20$ futura.pdf

Godet, M. (1999). De la anticipación a la acción. Manual de prospectiva y estrategia; Bogotá: Alfaomega S. A.

Godet, M. y otros (S/A). La caja de herramientas de la prospectiva estratégica: problemas y métodos. Recuperado de: http://lipsor.cnam. fr/jsp/fiche_pagelibre.jsp?STNAV=\&RUBNA$\mathrm{V}=\& C O D E=90419717 \&$ LANGUE $=0 \& \mathrm{RH}=$

Hamel, G. (2012). El poder del Ahora. Bogotá: Grupo Editorial Norma.

Kim C., y Mauborgne R. (2005). La estrategia del océano azul. Bogotá: Grupo editorial Norma.

Mintzberg, H. (2010). Managing. Bogotá: Grupo Editorial Norma.
Mojica, F. (1991). La prospectiva: técnicas para visualizar el futuro. Bogotá (s.e).

Ohmae, K. (2005). El Próximo Escenario Global - Desafíos y Oportunidades en un mundo sin fronteras. Bogotá: Grupo Editorial Norma.

Peña T. P. (2001). Prospectiva: una herramienta gerencial. Bogotá: Universidad Nacional de Colombia, Unibiblos.

Pérez -Uribe R. (2013). Gerencia estratégica corporativa: con aplicaciones para logística aeronáutica y gerencia de la seguridad aérea. Fuerza Aérea Colombiana. Instituto Militar Aeronáutico. Segunda edición, 319 p. ISBN: 978-958-99406-4-8.

Porter M. (1996). ¿What is Strategy. HBR 20 patinas, ingles. Harvard Business Review. Recuperado de: http://www.ipocongress.ru/ download/guide/article/what_is_strategy.pdf

Porter, M. (1998). Ventaja competitiva. México: Compañía Editorial Continental.

Wheelen, T., y Hunger; J. D. (2007). Administración estratégica y política de negocios. México: Pearson educación, Edición 26. 